\title{
LOSING WEIGHT TO SAVE LIVES: A REVIEW OF THE ROLE OF AUTOMOBILE WEIGHT AND SIZE IN TRAFFIC FATALITIES
}

\author{
Marc Ross and Tom Wenzel \\ July 2001 \\ Report Number ACEEE-T013
}

\begin{abstract}
An earlier draft of this report was submitted to
the National Research Council's Committee on Effectiveness and Impact of Corporate Average Fuel Economy (CAFE) Standards, March 13, 2001
\end{abstract}

This work was supported by The Energy Foundation. Prepared for the U.S. Department of Energy under LBL Contract No. DE-AC03-76SF00098. Report Number LBNL-48009

(C)American Council for an Energy-Efficient Economy 1001 Connecticut Avenue, NW, Suite 801, Washington, D.C. 20036 Phone: 202-429-8873, Fax: 202-429-2248, Web site: http://aceee.org 


\section{Authors' Affiliations:}

\section{Marc Ross \\ Physics Department \\ University of Michigan}

Tom Wenzel

Lawrence Berkeley National Laboratory

This document was prepared as an account of work sponsored by the United States Government. While this document is believed to contain correct information, neither the United States Government nor any agency thereof, nor The Regents of the University of California, nor any of their employees, makes any warranty, express or implied, or assumes any legal responsibility for the accuracy, completeness, or usefulness of any information, apparatus, product, or process disclosed, or represents that its use would not infringe privately owned rights. Reference herein to any specific commercial product, process, or service by its trade name, trademark, manufacturer, or otherwise, does not necessarily constitute or imply its endorsement, recommendation, or favoring by the United States Government or any agency thereof, or The Regents of the University of California. The views and opinions of authors expressed herein do not necessarily state or reflect those of the United States Government or any agency thereof, or The Regents of the University of California.

Ernest Orlando Lawrence Berkeley National Laboratory is an equal opportunity employer.

The U.S. Government retains a nonexclusive royalty-free license to publish or reproduce the published form of this contribution, or allow others to do so, for U.S. Government purposes. 


\section{Contents}

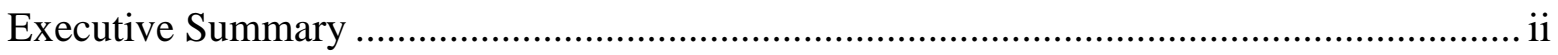

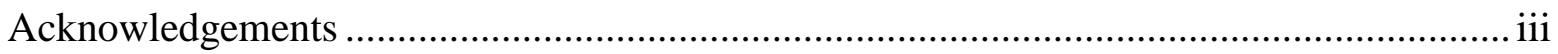

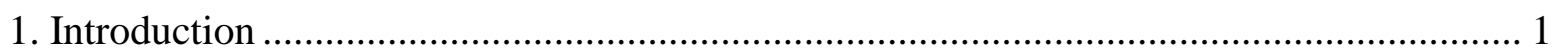

1.1. Trends in Automotive Safety ..................................................................... 1

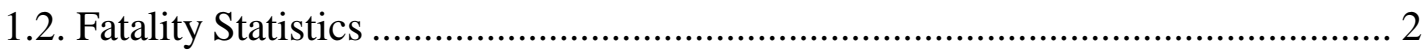

1.3 Fatality Statistics: for New Vehicles and per Vehicle ............................................ 7

1.4 Analytical Approach...................................................................................... 11

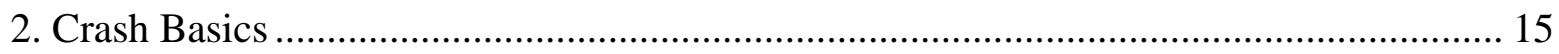

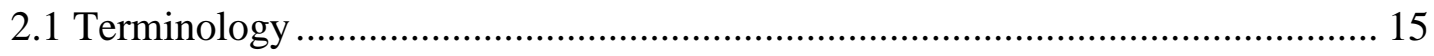

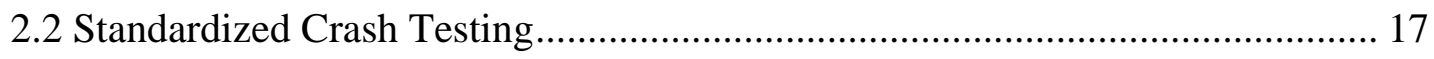

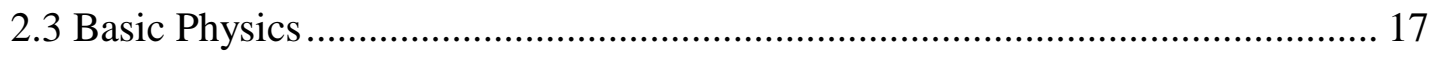

3. Review of Research on Fatalities in 2-Vehicle Crashes and Vehicle Mass ...................... 21

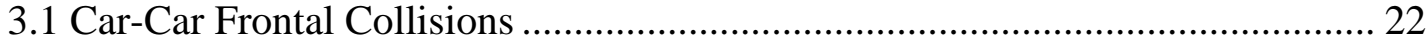

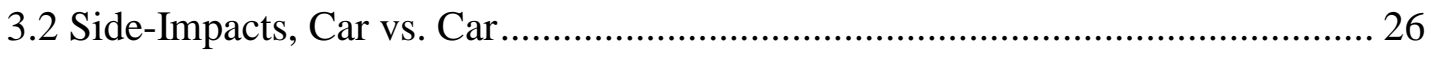

3.3 Cars vs. Light Trucks .............................................................................. 26

4. Review of Research on Safety and Making Vehicles Lighter/Smaller ............................. 28

4.1 Analysis of Weight Reduction Based on Fatality Statistics ............................... 28

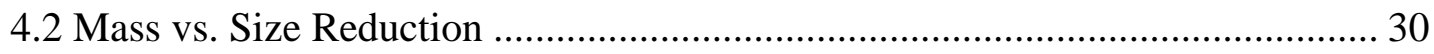

4.3 Light Car Design Studies ............................................................................... 31

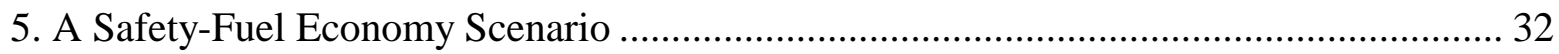

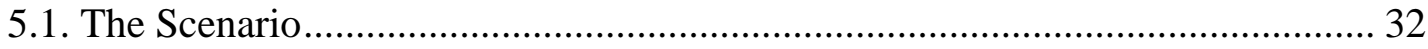

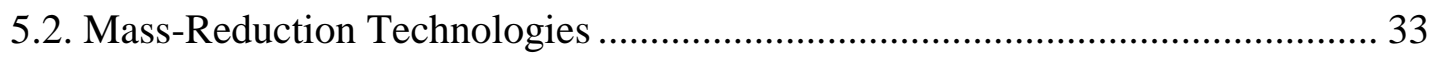

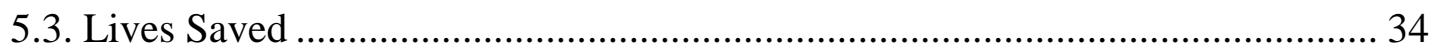

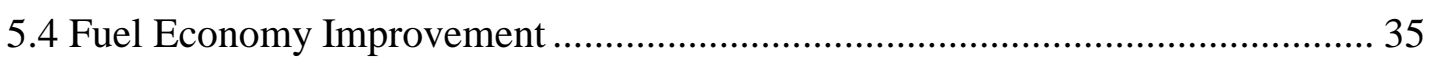

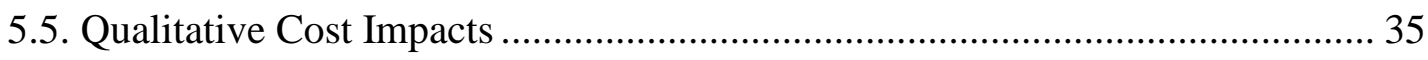

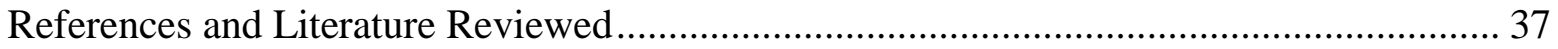




\section{Executive Summary}

Reductions in vehicle weight will be necessary to dramatically increase vehicle fuel economy and address concerns about global warming. The purpose of this report is to explore the relationship between vehicle weight and fatalities in traffic accidents. One of the most interesting possibilities is to use new technologies to reduce vehicle weight while maintaining vehicle size to protect occupant safety. ${ }^{1}$

Two-vehicle crashes are the largest source of traffic fatalities, accounting for $43 \%$ of traffic fatalities in 1999. Fatalities in car-to-car crashes have sharply declined even while the number of cars on the road has gradually increased. Car-to-car head-on fatalities dropped 35\% in the 1980s and did drop another $25 \%$ in the 1990s. If one looks at fatalities in new cars only, the decline is even more rapid-an $80 \%$ decrease for 1980-97! The consequences of car-to-car head-on fatalities have been revolutionized by protection technology, motivated in part by the standardized crash test. Seat belts and air bags are increasingly effective in protecting occupants. Powerful computer-assisted efforts also enable safety improvements in the design and manufacture of vehicle structures.

Light trucks crashing with cars now cause many more fatalities than cars crashing with cars. Collisions where trucks strike cars on the side are now the largest cause of fatalities in twovehicle crashes. Over two thousand lives would be saved annually by establishing "compatibility" between cars and light trucks. ${ }^{2}$ This means reducing the mass differential between cars and those light trucks used as car substitutes by making the heavier vehicles lighter. Compatibility in height and stiffness is also required-for example, for the front of the striking vehicle (truck) and the side of the struck vehicle (car). Compatibility involves both vehicles: The lighter cars would not be made still lighter, but would be made larger in selected ways.

Such changes can be achieved with the help of mass-reduction technologies. First, the basic structure of light truck car-substitutes that are now body-on-frame would instead be unibody (like today's cars) or perhaps space frame. Second, the use of lightweight materials (such as high- and ultrahigh-strength steels, aluminum, and engineering plastics) would be emphasized. Third, high-efficiency propulsion systems would be much lighter. These technologies include: (1) small displacement engines with a much higher ratio of power-to-displacement; (2) automatic transmissions that function smoothly without a torque converter (with sophisticated motor-shifted standard transmission or continuously variable transmission); and (3) on-shaft starter-generators with a 42 volt (V) electrical system, enabling idle-off and other modest hybrid-drive capabilities without a heavy battery.

There are also many deaths in one-vehicle crashes- $31 \%$ of all fatalities are from collisions with stationary objects like trees, parked cars, and utility poles. Fatalities in these crashes have

\footnotetext{
${ }^{1}$ The terms "weight" and "mass" are used interchangeably. "Smaller," "larger," and "size" refer to spatial dimensions, while "lighter" and "heavier" refer to mass.

${ }^{2}$ However, quantitative forecasts of the lives saved overall by the safety strategy recommended here are rough because there are no definitive statistical analyses available to quantitatively assess the increase in safety of vehicle weight reduction separately from size.
} 
also declined, perhaps for similar reasons as the decline in car-to-car crash fatalities, although the decline has not been as rapid. Progress could continue in the face of mass (but not size) reduction because cars that are "overweight" for their size do not appear to offer significant added protection.

Some $12 \%$ of fatalities in cars and light trucks occur in "non-collision" events, mostly rollovers following driver loss of control. The likelihood of a rollover is increased by certain design features, such as high center of mass, narrow track width, and softness of suspension with respect to roll. The likelihood is also increased by a high load, like passengers and luggage in an sport utility vehicle (SUV) with its high floor. The historical correlation in cars of light weight with rollovers is not inherent, but a matter of design. In new model cars, this correlation has essentially disappeared. With rollover tests and standards, design changes will also be made to reduce rollovers in light trucks.

In Europe, efforts to develop extremely light/small vehicles (by U.S. standards) are leading to the development of relatively effective protection systems for that vehicle class, although it appears that the safety technology may increase both cost and weight. The European studies we have seen have not examined the option of maintaining or even increasing size while reducing vehicle weight using new lightweight materials.

Our conclusions regarding the impact of reducing vehicle weight on vehicle safety are:

(1) The high mass ratio of most "light" trucks over cars is an inherent aspect of incompatibility in crashes. Reduction in the mass and other incompatibilities of the light trucks would result in a major decrease in car fatalities and in fatalities overall.

(2) Moreover, increasing size in selected ways, such as increased crush space and stiffness at the sides, is likely to be a powerful technique for reducing traffic fatalities.

In a nutshell, from a safety perspective the United States needs to resolve the incompatibility of light trucks with cars and it needs to continue development and adoption of powerful crash mitigation and avoidance technologies. Making heavier vehicles lighter (but not smaller) and making lighter cars larger (but not heavier) would not only increase safety but also increase fuel economy. We project a fuel economy increase of over $50 \%$ in association with these safety measures.

\section{Acknowledgements}

We thank The Energy Foundation for supporting this work. We thank our colleagues at the University of Michigan Transportation Research Institute, including Ken Campbell, Charles Compton, Hans Joksch, and Matthew Reed, for teaching us a great deal about vehicle safety. We thank Maureen Kreple for assistance. We thank Therese Langer for a critical reading of the "final" report. We also thank John DeCicco, Mark Delucchi, and Steven Plotkin for helpful comments on a draft version of this report. However, all responsibility for inaccuracies and opinions rests with the authors. 


\section{Introduction}

Critics of higher fuel economy standards for vehicles have long argued that improving vehicle fuel economy will require reducing vehicle weight, and that that would result in an increase in the number of fatalities from vehicle crashes. ${ }^{3}$ Several researchers have estimated that an acrossthe-board reduction of vehicle weight would reduce passenger safety (Evans 1991; Kahane 1997; U.S. GAO 1994). However, little research has been done on the relationship of vehicle size and fatality rates, independent of weight (see, however, Joksch, Massie, and Pichler 1998).

In this report we review previous analyses of the relationship of vehicle weight and safety. We do this to study the opportunities to improve fuel economy in a more sophisticated way than acrossthe-board mass reduction. The aim is to explore improvements in traffic safety by making selected vehicle groups lighter, and retaining or enlarging selected vehicle dimensions. Unfortunately, the effects of size and mass have not been accurately separated in the crash fatality data, so some of our claims are only supported by general arguments from physics. In a follow-up report we will attempt to analyze crash fatality data to determine crashworthiness if the weight of certain vehicle groups would be decreased while maintaining or increasing vehicle size.

The first section of this report provides an introduction to fatal vehicle crashes in the United States. We summarize several trends in automotive crash statistics over the last 20 years. Then we discuss approaches analysts have taken in studying factors that affect "exposure", the likelihood of being involved in a serious crash. In Section 2 we discuss standardized crash tests and the basic physics of crashes. We review previous research on the effect of vehicle mass in two-vehicle crashes in Section 3. We also present new research on reductions in risk achieved by recent light vehicles. Section 4 presents previous estimates of the effect of reductions in vehicle mass and size on the number of fatalities overall. Section 5 presents our scenario for making light duty vehicles safer while improving fuel economy.

\subsection{Trends in Automotive Safety}

Two things are happening that are dramatically altering automotive safety: (1) safety technology is continuing to progress rapidly, saving lives and incidentally rendering older safety analyses obsolete; and (2) light duty trucks have become a major part of the automotive fleet and, in most designs adopted, have proven "incompatible" with the safety of occupants of conventional passenger cars. ${ }^{4}$

Changes in automotive technology today are much more rapid than they were even a decade ago. The new safety technologies discussed by the 1992 National Research Council fuel economy panel have largely been implemented (National Research Council 1992, pp. 58-60). Other safety technologies are now being developed and deployed. Changes are so rapid that evaluations based

\footnotetext{
${ }^{3}$ We use the term "crash" to refer to collisions between vehicles as well as vehicle rollovers and crashes between vehicles and stationary objects, pedestrians, and pedal-cycles.

${ }^{4}$ In the terminology of this report, cars are passenger cars like sedans, coupes, and station wagons; light trucks are vans, pickups, and SUVs.
} 
on past performance must be viewed with caution. There are two major areas of technological change with respect to the safety of vehicle occupants.

First, the impact of crashes is being mitigated. Seat belt use has substantially increased (Table 1.4, below). More sophisticated and effective internal restraints are being, or will soon be, installed in all market segments. Airbags in new locations and improved airbags have been well publicized. Also of great potential importance are changes in seat belt design, like belts with four anchors, pretensioning belts (which are beginning to be adopted), and load-limited belts (Bendjellal et al. 1997). Parts of the vehicle with which occupants are likely to collide in a crash are being redesigned with the help of computer-aided design. New materials will change the old relationships between vehicle dimensions and mass; for example, crush space can be increased without increasing mass. The incompatibility of different vehicles in collisions is being systematically studied, and it is hoped that those studies will lead to major changes in vehicle geometry and stiffness.

Second, crash avoidance technology is becoming increasingly effective and there remains great potential to further reduce fatalities. Highway design and management has had great successes in reducing fatalities and severe injuries. Driver vision is being improved. Driver alertness is likely to be monitored. Faster, partially automated braking is being developed. Automatic observation of deviation from lane following, and alerts to drivers, are in development. And so on.

We do not claim that vehicles similar to today's light trucks are inherently incompatible with cars; with adequate changes in design they should not be. Nor do we believe that crash fatalities will be eliminated by safety technology. Our point is that historical patterns and relationships are in flux. At present, only the most robust and recent information from automotive crash statistics can be safely used as a guide for fully reliable estimates of the relationship between vehicle design and safety.

\subsection{Fatality Statistics}

For simplicity we focus on fatality statistics. The most important database used in the analyses reviewed here is the 1999 Fatality Analysis Reporting System (FARS) database produced annually by the National Highway Traffic Safety Administration (NHTSA) of the U.S. Department of Transportation. FARS includes a record of essentially all fatal highway crashes, with about 340 variables for each. It also includes detailed information on each vehicle and driver involved in each crash.

The historical record of traffic fatalities shows a gradual declining trend over the past 33 years, as shown in Figure 1.1. The total number of fatal crashes and fatalities declined 18\% from 1979 to 1999 even though the number of vehicles in use increased 55\% and the vehicle miles traveled increased $75 \%$. (The dips in Figure 1.1 are associated with gasoline price hikes and economic recessions.) The figure also shows that fatalities per driver fell more than half during this period. Driving in the United States is safer than in almost all other major countries; nevertheless, the toll of severe injuries and fatalities is unacceptably high. Fortunately, the structure of fatal crashes reveals major opportunities for continued reductions in fatalities. 
Table 1.1 shows the number of vehicles and fatalities involved in fatal crashes in 1999, by vehicle type. Occupants of cars and light trucks accounted for $89 \%$ of the fatalities. The advantage for occupants of heavier vehicles (such as light trucks, buses, and heavier trucks) is evident when one compares the distribution of vehicles and fatalities; for instance, buses and heavy trucks are involved in $9 \%$ of the fatal crashes, but their occupants account for only $2 \%$ of the fatalities. Conversely, cars are involved in only $49 \%$ of the crashes, but $58 \%$ of fatalities are car occupants; motorcycles are involved in only $4.8 \%$ of the crashes, but $7.4 \%$ of the fatalities are motorcycle riders.

Figure 1.1 Total Traffic Fatalities and Fatalities per Million Licensed Drivers, 1966-1998

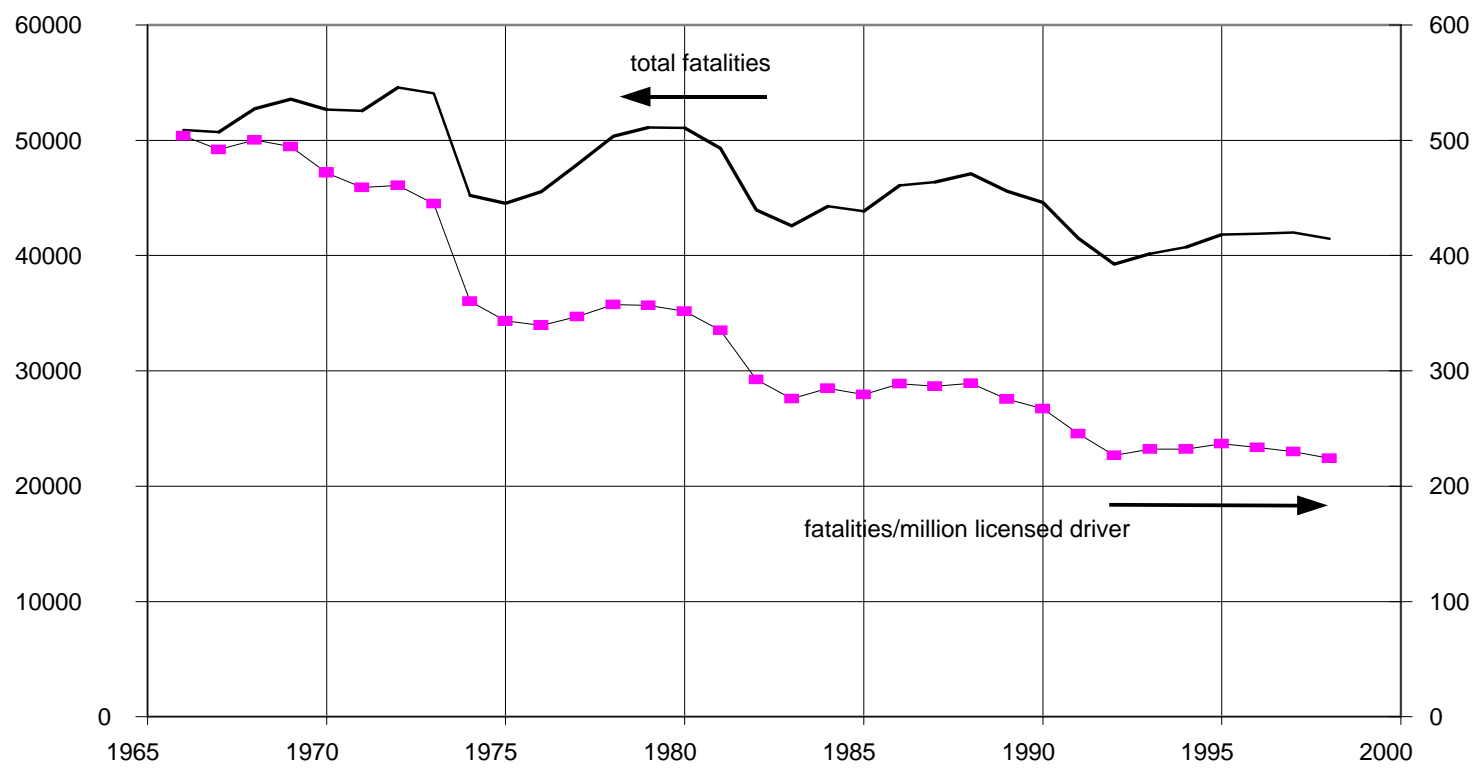

Table 1.1 Vehicle Types Involved in Fatal Crashes, 1999

\begin{tabular}{|l|cc|c|c|}
\hline \multirow{2}{*}{ Body Type (110) } & \multicolumn{2}{|c|}{$\begin{array}{c}\text { Vehicles } \\
\text { Fatalities* }\end{array}$} & \multicolumn{2}{c|}{$\begin{array}{c}\text { Fo } \\
\text { to Vehicle Occupants }\end{array}$} \\
\cline { 2 - 5 } & Number & Percent & Number & Percent \\
\hline \hline Cars & 27,955 & $49 \%$ & 20,818 & $58 \%$ \\
Light trucks (<10,000 lb. GVW) & 19,953 & $35 \%$ & 11,273 & $31 \%$ \\
Buses and heavier trucks & 5,273 & $9 \%$ & 831 & $2 \%$ \\
Motorcycles & 2,705 & $5 \%$ & 2,643 & $7 \%$ \\
Other and unknown & 782 & $1 \%$ & 241 & $1 \%$ \\
Total & 56,668 & $100 \%$ & 35,806 & $100 \%$ \\
\hline
\end{tabular}

* An additional 5,805 fatalities occurred when a motor vehicle struck pedestrians, cyclists, or occupants in parked vehicles.

Table 1.2 shows the distribution of crashes and fatalities in 1999 by type of crash, as defined by the "first harmful event" coded in the FARS database. Setting aside fatal crashes with pedestrians and bicyclists, essentially half are two-vehicle collisions and half are one-vehicle crashes. The latter is mostly crashes with objects like trees, guardrails, and utility poles, but 
there is also a substantial number of fatalities from primary rollovers (due to driver's loss of control rather than to a collision). The high rate of light truck rollover fatalities can be seen. (Crashes are often complex, so categorization varies as seen in comparing Tables 1.1 and 1.2.)

Table 1.2 Number of Fatalities and Number of Vehicles by First Harmful Event, 1999

\begin{tabular}{|l|c|c|c|c|}
\hline \hline & & \multicolumn{3}{|c|}{ Number of Vehicles* } \\
\cline { 3 - 5 } & Fumber of & & $\begin{array}{c}\text { Light } \\
\text { trucks }\end{array}$ & Other \\
\hline \hline $\begin{array}{l}\text { 2- or more vehicle collision } \\
\text { 1-vehicle collision with objects other }\end{array}$ & 12,916 & 7,024 & 4,025 & 1,426 \\
$\quad$ than vehicle in transport & & & \\
Non-collision (80\% are initial & & & & \\
$\quad$ rollovers) and unknown & 4,809 & 1,433 & 2,390 & 731 \\
Subtotal & & & & \\
Crash with pedestrian/pedal-cycles & 35,266 & & & \\
Total & 5,831 & 2,804 & 1,977 & 835 \\
\hline
\end{tabular}

*Excludes additional vehicles and their fatalities in collisions involving more than two vehicles.

The history of fatalities by type of crash is shown in Figure 1.2. Fatalities in one-vehicle crashes declined moderately even while the number of vehicles increased by about half in this 20 -year period. Fatalities in two-vehicle crashes increased slightly in recent years even while car-car crashes became much safer, in association with the aggressivity of light trucks, as discussed below. Fatalities among pedestrians and bicyclists declined sharply, perhaps due to improved road and intersection design. One-vehicle "non-collision" fatalities (mostly rollovers) declined but have been increasing lately due to the rollover tendency of some SUVs.

In Figure 1.3 the history of driver fatalities in two-vehicle collisions is shown by percentages, where both vehicles are cars or light trucks only. There has been a dramatic decline of fatalities in car-to-car collisions, accompanied by a rise in the fatalities involving light trucks. There are two reasons: (1) the fraction of light trucks on the road has increased from $19 \%$ to $36 \%$ of all light duty vehicles on the road (U.S. TEDB 2000); and (2) car-to-car crashes have become much safer while car-light truck crashes have become only modestly safer. Car-light truck collisions are now the largest source of fatalities in two-vehicle collisions. 
Figure 1.2 History of Fatalities by Type of Crash, 1980-99, from FARS

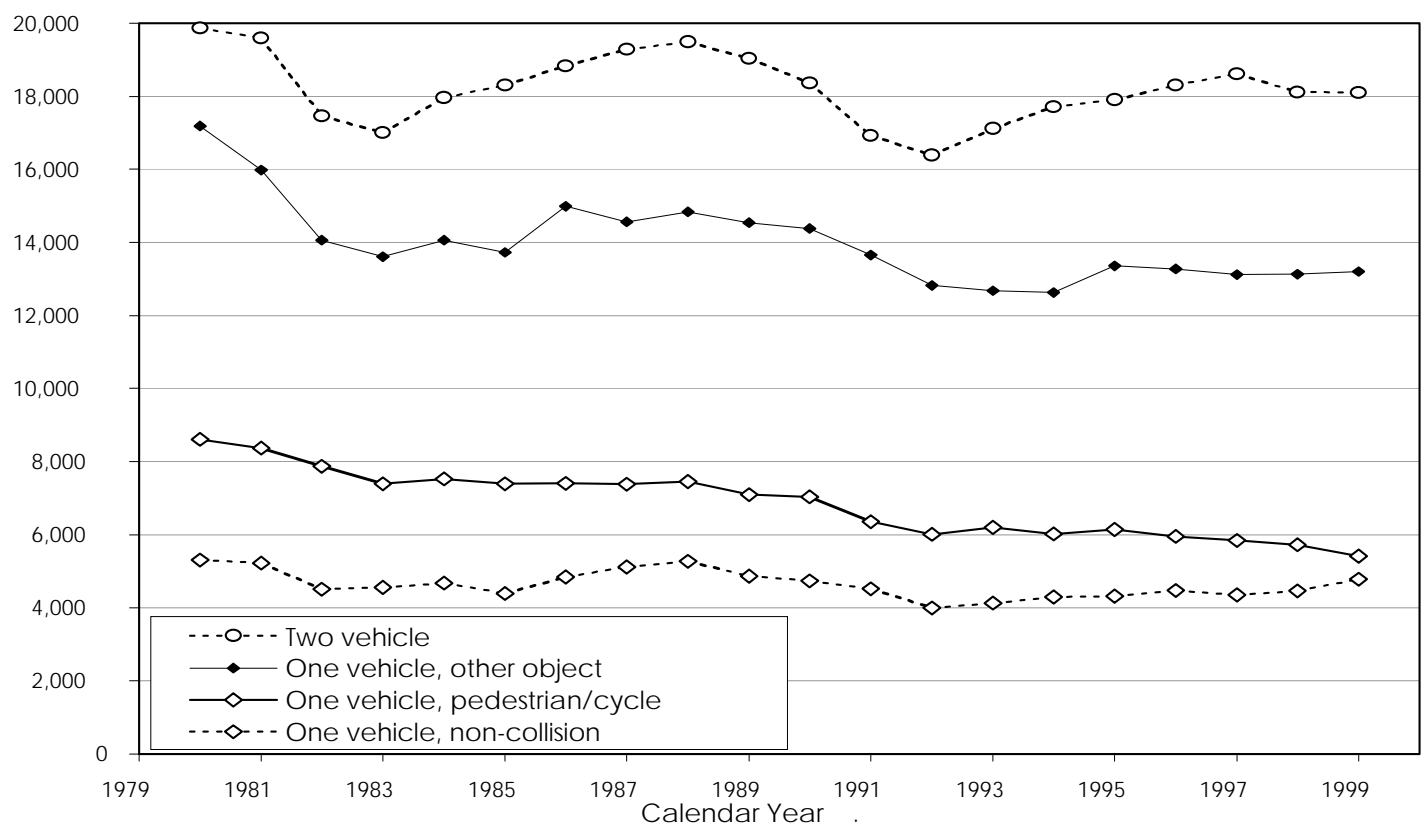

Figure 1.3 Fraction of Driver Fatalities in Two-Vehicle Collisions Involving Cars and Light Trucks Only (1980-99, from FARS) And Fraction of All Light Duty Vehicles That Are Trucks

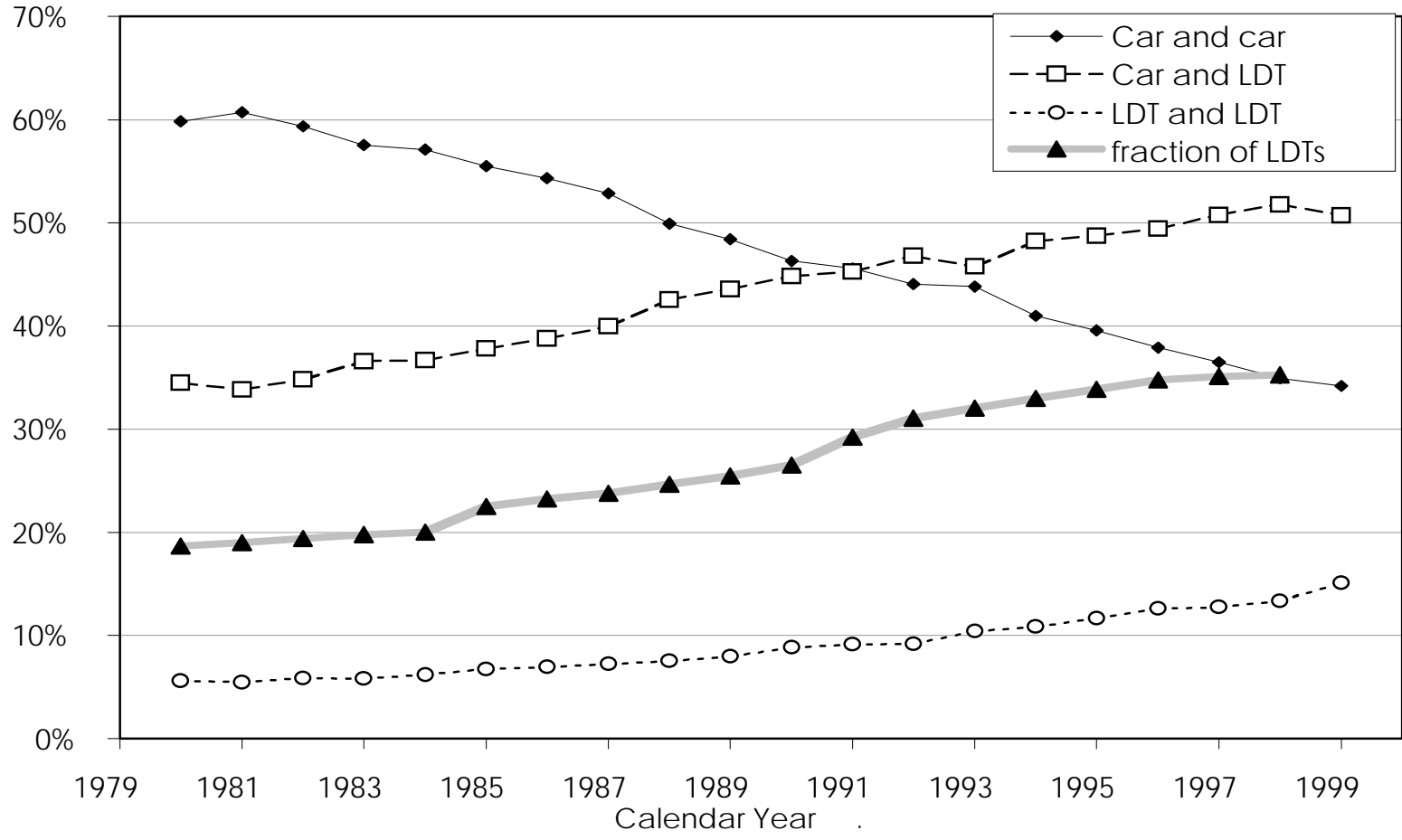


An estimate of the additional deaths due to the substitution of light trucks for cars is presented below in Section 3.3.

Figure 1.4 shows the number of driver fatalities in the two main types of two-vehicle crashes: head-on vs. side-impact. Fatalities in head-on car-to-car collisions declined more than half during the 20-year period even while the number of cars on the road increased moderately and miles driven probably did not change substantially. Meanwhile, side-impact fatalities are becoming more important than frontal impacts.

Figure 1.4 Number of Driver Fatalities in Car-to-Car Collisions, by Main Configuration, 1980-99, from FARS

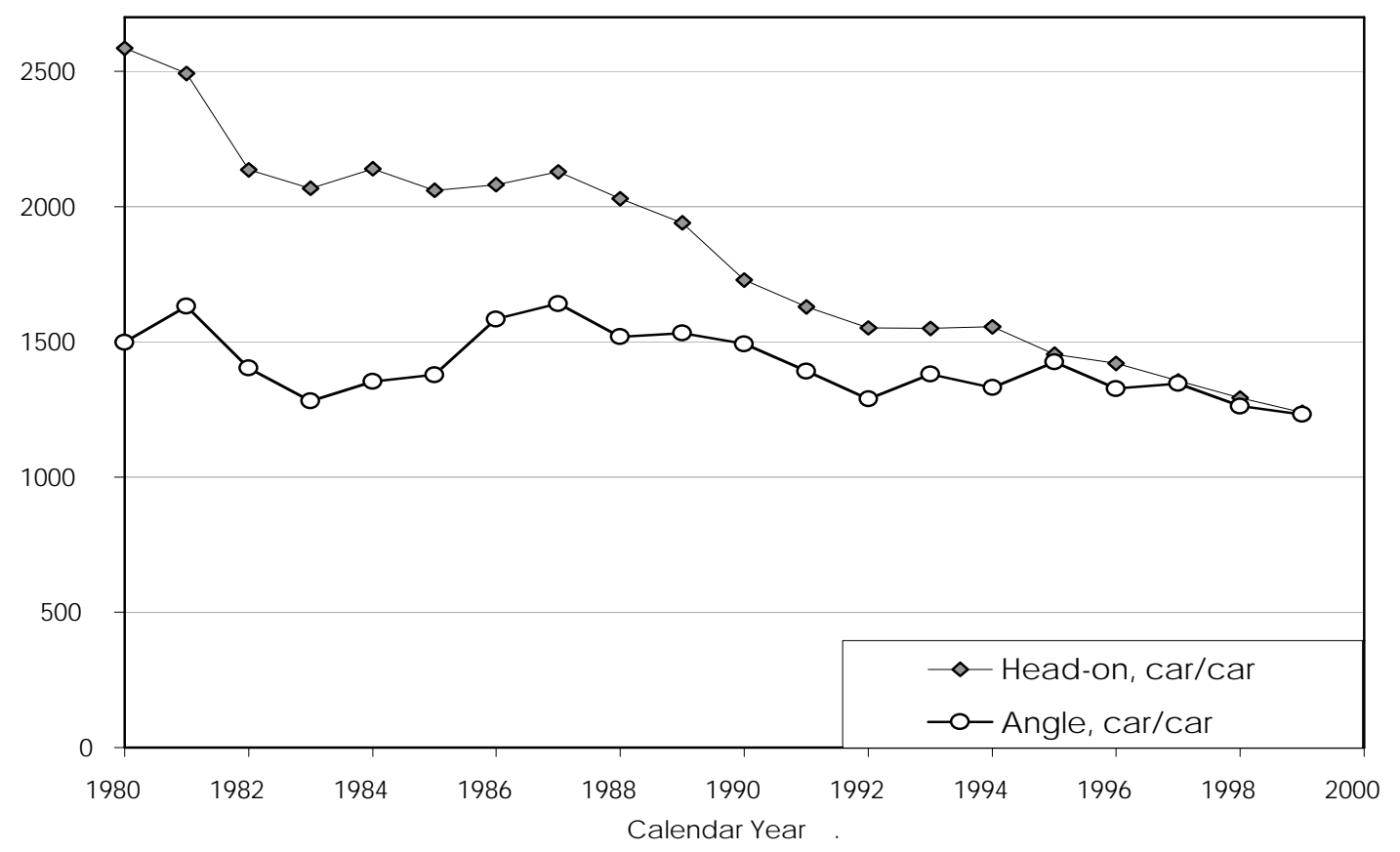

In Table 1.3, the vehicle configuration in two-vehicle crashes is shown for 1999. There are now more deaths in side-impact ("angle") collisions than in head-on collisions. The major role of light trucks in two-vehicle fatalities is again evident. 
Table 1.3 Number of Fatalities in Two-Vehicle Collisions, by Manner of Collision and Vehicle Type, from FARS 1999

\begin{tabular}{||l|c|c|c|c||}
\hline \multirow{2}{*}{$\begin{array}{c}\text { Manner of } \\
\text { Collision }\end{array}$} & $\begin{array}{c}\text { Number of All } \\
\text { Fatalities } \\
\text { Involving Two } \\
\text { Vehicles* }\end{array}$ & $\begin{array}{c}\text { Number of Fatalities* } \\
\text { Car-to- } \\
\text { Car }\end{array}$ & $\begin{array}{c}\text { Car-to- } \\
\text { Truck }^{\dagger}\end{array}$ & $\begin{array}{c}\text { Truck-to- }^{\text {Truck }} \\
\text { Trund }^{\dagger}\end{array}$ \\
\hline \hline Head-on & 6,544 & 1,774 & 2,423 & 820 \\
\hline Angle & 8,347 & 1,915 & 3,099 & 717 \\
\hline Rear-end & 1,966 & 306 & 493 & 175 \\
\hline Other and unknown & 687 & 308 & 364 & 122 \\
\hline Total & 17,544 & 4,303 & 6,379 & 1,834 \\
\hline
\end{tabular}

*Excludes additional vehicles and their fatalities in collisions involving more than two vehicles.

$\dagger$ light trucks

Seat belts are considered to be the most important safety technology. The importance of seat belts in reducing fatalities is evident comparing seat belt use by drivers killed in crashes with that observed in the careful National Occupant Protection Use Survey. Seat belt use is roughly half as great among drivers killed as among all drivers! Part of the effect is that careless drivers are also less likely to use seat belts.

Table 1.4 Seat Belt Use in Percent

\begin{tabular}{||c|c|c|}
\hline & FARS 1999* & NOPUS (2000) \\
\hline \hline Passenger Cars & 41 & 75 \\
drivers & & 70 \\
passengers & 30 & 75 \\
\hline Vans and SUVs & & 72 \\
drivers & & \\
passengers & 21 & 61 \\
\hline Pickup Trucks & & 55 \\
drivers & & \\
passengers & & \\
\hline
\end{tabular}

* seat belt use in fatalities

\subsection{Fatality Statistics: for New Vehicles and per Vehicle}

\subsubsection{Two-Car Collisions}

In this section, we examine fatalities by model year for new cars (1 or 2 years of age) in order to focus on developments up to the late-1990s model years. We also examine fatalities per vehicle, i.e., using the number of vehicles 1 and 2 years of age as the denominator.

In Figure 1.5, annual driver fatalities in car-car crashes are shown for the two main configurations, as in Figure 1.4. In the final decade shown, head-on fatalities in car-to-car 
collisions dropped $65 \%$ and angle (or side-impact) collisions dropped 45\%. Fatalities in angle collisions became larger than those in head-on collisions.

Dividing the fatalities by the number of new cars in each model year, one obtains the fatalities in car-car crashes per million cars, as shown on the right-hand scale. ${ }^{5}$ The general trend in fatalities per car is the same as for fatalities because car sales were roughly constant in this period. We find the extraordinary result that deaths in new cars from car-to-car headon collisions were only a third as great in 1998 as one decade earlier, and only 20\% as great as in 1980.

\section{Figure 1.5 History of Annual Driver Fatalities in Car-Car Collisions where the Vehicle with the Fatality is One or Two Years Old, by Main Configuration; Also Fatalities per New Car}

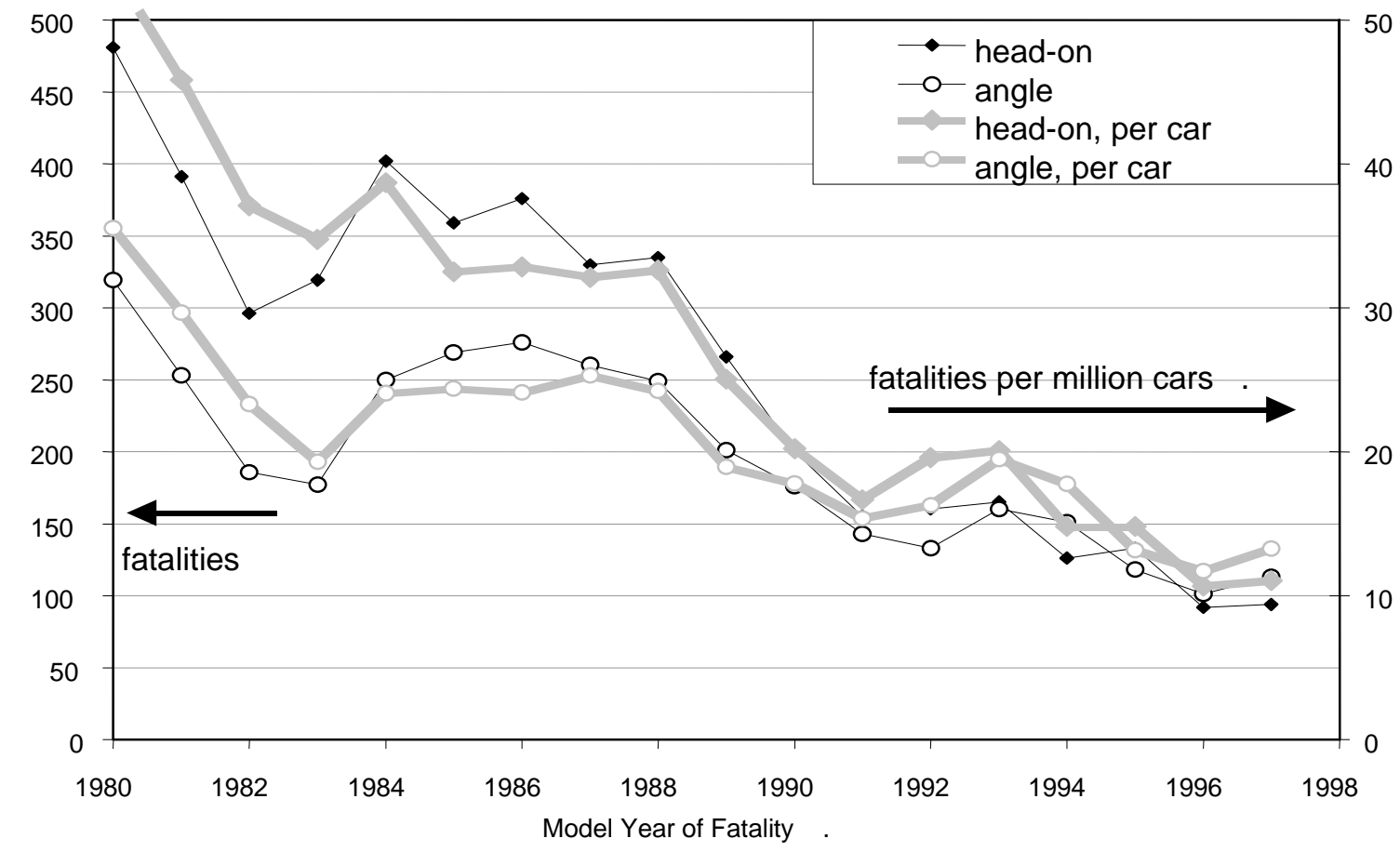

The corresponding calculations for car-truck and truck-truck collisions (not shown) are less conclusive because of uncertainties associated with the rapid increase in truck population and with choice of denominator. These histories also show a relative growth in side-impact fatalities.

\footnotetext{
${ }^{5}$ The deaths per vehicle measure shown in Figure 1.5 is affected by the number of cars available to be struck by a new car or truck. In fact, the number of cars in use increased moderately during these two decades, a total of $18 \%$ in the 1980s and 3\% in the 1990s (Ward's 2000 and earlier years). By itself this might suggest that the deaths per vehicle should have increased. Probably the fatalities per new vehicle, in these new vehicle-to-car collisions, were not strongly affected by the total car population.
} 


\subsubsection{One-Vehicle Collisions with an Object}

Now consider fatalities in one-vehicle collisions with a stationary object (excluding "noncollisions" like principal rollovers). Driver fatalities in these one-vehicle collisions are shown in Figure 1.6. The vehicle with a fatality is 1 or 2 years old. The fatalities per million vehicles are similar for cars and trucks. This is not surprising since most light trucks are simply car substitutes, driven roughly the same way and encountering similar fatality risks when they strike an object. However, there is some improvement in the fatality rate of trucks relative to cars. This might be an averaging effect, associated with the adoption of SUVs during this period: SUVs are less dangerous than pickups. The data are not corrected for driver age and gender.

Figure 1.6 Driver Fatalities in One-Vehicle Crashes with a Stationary Object. Light Duty-Vehicles Are 1 or 2 Years Old, 1980-99, from FARS

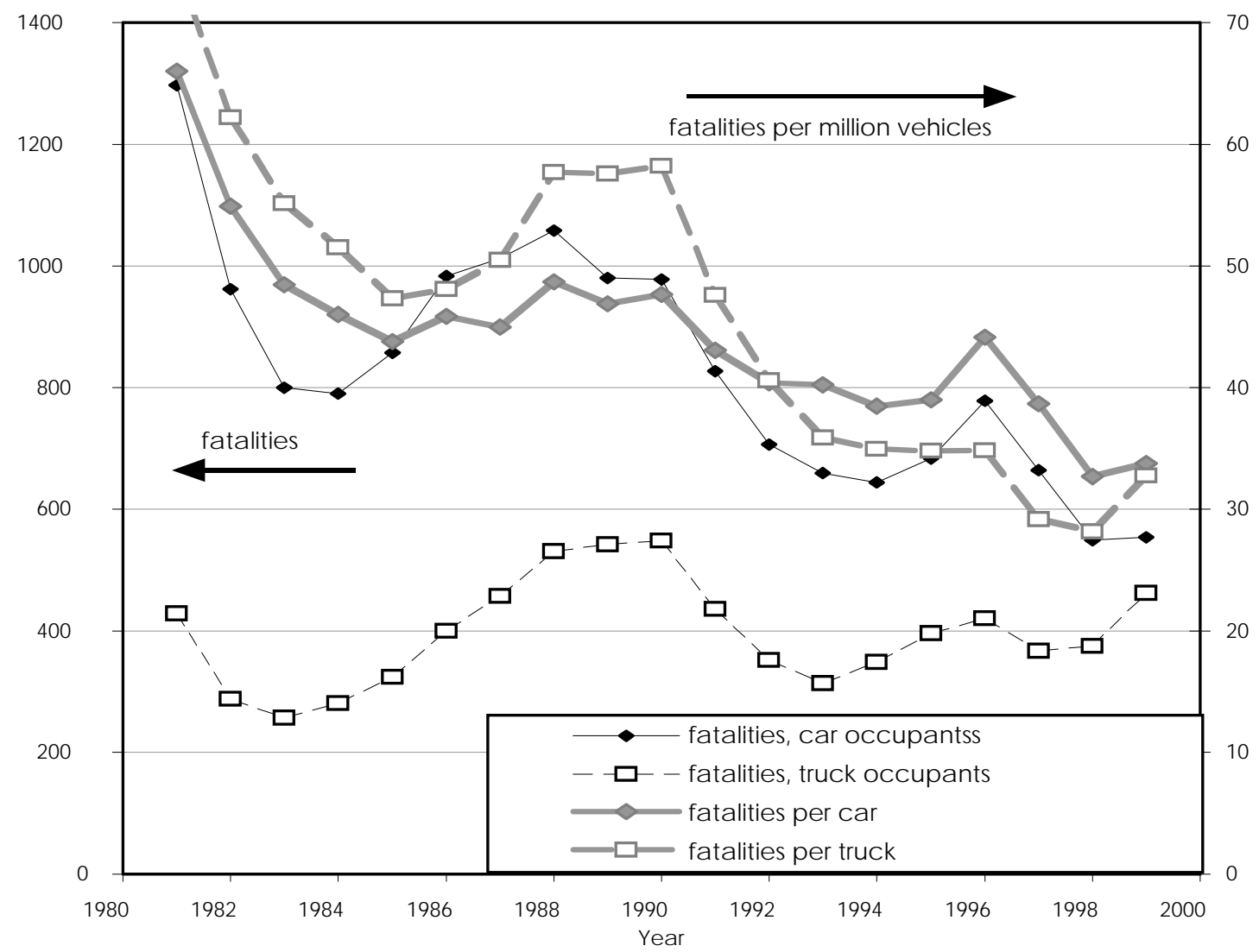

In Table 1.5, the main results from Figures 1.5 and 1.6 are abstracted. The driver fatalities in new vehicles, per vehicle, decreased strongly, most strongly for head-on car-car collisions, less strongly for side-impact car-car collisions, and still less strongly for collisions with stationary objects. It may be relevant that standardized testing programs have emphasized those types of crashes in that order. 
Table 1.5 Decline in Driver Fatalities per Vehicle, for Vehicles 1 and 2 Years Old

\begin{tabular}{|lcc|}
\hline \multicolumn{1}{|c|}{ Kind of Crash } & Denominator & Decrease 1987-1997 \\
\hline \hline car-car head-on & new cars & $65 \%$ \\
car-car side-impact & new cars & $45 \%$ \\
car collision w/stationary object & new cars & $30 \%$ \\
truck collision w/stationary object & new trucks & $35 \%$ \\
\hline
\end{tabular}

\subsubsection{Rollovers}

FARS distinguishes between rollovers as the first event (also called primary rollovers) and rollovers during subsequent events. Rollover fatalities in these two types were $36 \%$ and $64 \%$, respectively, in 1999. Except for the tendency of (some) SUVs to be involved in fatal rollovers, the history of rollover fatalities (not shown) is irregular and not very revealing, perhaps because of changing interpretations by investigating officers, or poor statistics.

Kahane (1997) and U.S. GAO (1995) estimate that the greatest percentage increase in risk associated with a weight reduction in cars is from rollovers since the lightest cars in the 1980s were prone to rollover. Figure 1.7 shows that the tendency of cars of low weight to predominate in rollover fatalities in the $1980 \mathrm{~s}$, but that this tendency has greatly diminished in the 1990s model years. The likelihood of rollovers depends primarily on design features, such as height of center of mass, track width, and stiffness of suspension with respect to roll (Gillespie 1992). The historical correlation of such features with weight is not inherent, but a matter of design (as Kahane notes in his study). With rollover standards, design changes will be made to reduce rollovers for light trucks as well as for cars. 
Figure 1.7 Average Curb Weight of Cars in One-Car Fatal Crashes by Model Year, and Comparison with EPA Sales-Weighted Average

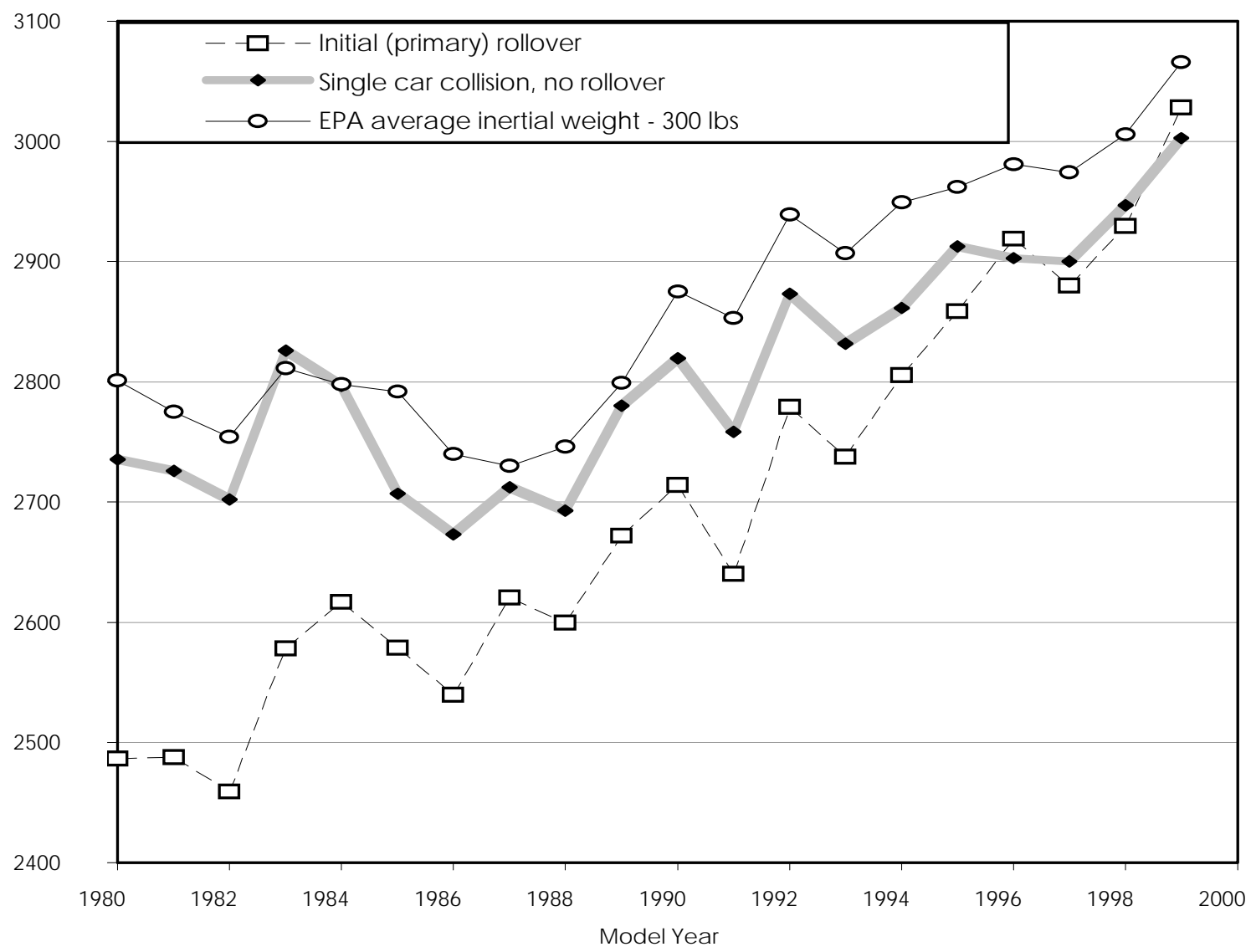

Note: The EPA weight is the inertial weight less $300 \mathrm{lbs}$. The average weight of cars involved in pedestrian deaths, probably not biased toward light cars, is presented for comparison.

\subsection{Analytical Approach}

Most analyses of the role of vehicle type and design in crash fatalities are based on statistics of actual crashes. Although the application of mechanics and biomechanics is valuable, crashes and the reactions of human beings to them are complex. Thus, strong results based on experience tend to be more convincing than theory. However, statistical analyses of highway crashes depend on the existing system of vehicles, drivers, and roadways; they do not reflect the system as it will be in the future. And they do not fully reflect the impacts of recent safety technology, nor the rising impact of SUVs on fatalities. Since we seek to understand the consequences of fairly substantial changes to the vehicle fleet, we must also seek guidance from theory and standardized tests that have general implications, or those we believe are sensitive to future developments.

Another issue is the scope of analysis. A program that evaluates serious injuries and fatalities in automotive crashes should address three questions (adapted from Nash 1993): 
(1) What are the key factors that affect the likelihood that a vehicle will be involved in a serious crash? For example, certain vehicles have a narrow track width and so may be more likely to be in rollover events. We briefly discuss aspects of this question, but do not analyze it.

(2) When a specific crash occurs, what are the key factors that affect the likelihood of serious occupant injury? Here it is clear that occupants of larger, more massive cars and trucks have lower injury/fatality rates. The different roles of size and mass are at the center of our concern; they have not yet been definitively separated in analyses.

These two questions are important to an individual's quest for a safer vehicle. And there are many other factors that go into insuring one's safety on the road. From society's perspective, however, these two questions are secondary to the question: How can motor vehicle safety be improved for the public as a whole? That is:

(3) What is the effect of changes in characteristics of the vehicle fleet on the total number of severe injuries and fatalities, e.g., including the effects of one vehicle on the passengers of other vehicles? These characteristics include the distribution of vehicle sizes and mass over the entire fleet of vehicles. Illuminating this third question is our major goal.

\subsubsection{Exposure vs. Risk of Fatality given a Crash}

We are interested in how differences in vehicle design affect vehicle safety. Existing fatal crash data are the primary source of information. Let us say that we wish to compare the safety of a vehicle of Type A relative to that of Type B, and that fatal crashes are more common for A than B. However, such raw numbers are not very useful in themselves because there may be more vehicles of Type A, Type A vehicles may be driven more miles in a year than Type B, Type A may be driven by more dangerous drivers (such as young males), or Type A may tend to be driven at higher speeds on more dangerous roads (such as rural roads other than freeways). Factors like these strongly affect the number of serious crashes. The exposure of vehicles of Type A to serious crashes is critical to interpreting what fatal crash data can tell us about the risk of using that vehicle.

Table 1.6 lists some major exposure variables. It also shows driver and collision variables that can increase the likelihood of a fatality given a collision of a certain impact. Qualitatively, one should think of the risk of a fatality as the product of the risk of a crash of given severity, and the risk of fatality given that crash:

$$
\mathrm{R}(\text { fatality })=\mathrm{R}(\text { crash }) \cdot \mathrm{R}(\text { fatality } \mid \text { given the crash })
$$

Often analysts choose the total number of vehicles as the base exposure variable because it is understood by everyone and the information is readily available. The risk of a crash, $\mathrm{R}$ (crash), is then expressed per registered vehicle per year. Alternatively, analysts might prefer to use annual miles traveled, but accurate mileage information is usually not available. 
Conveniently available data is often the key. ${ }^{6}$ Some variables that can strongly affect exposure to a potential collision are reviewed in Table 1.6. Information on two of the most important factors, speed and driver care, are not accurately available. For speed, only speed limits are typically known. Also, analysts are essentially unable to deal with driving abilities/practices that are not identified by simply available characteristics like age and gender.

Table 1.6 Examples of Important Exposure and Risk of Injury Variables and Data Availability

\begin{tabular}{||lcc|}
\hline \multicolumn{1}{|c|}{} & High Risk Example & Quality of Data \\
\hline \hline Exposure (likelihood of severe crash) & & good \\
driver age & young drivers & good \\
driver gender & male & good \\
type of road: freeway vs. other & non-freeway & difficult \\
rural vs. urban & rural & marginal \\
travel speed & high speed & poor \\
carefulness of driver & prior violations & poor \\
Risk of Fatality, given the crash & use of alcohol & \\
driver age & & good \\
driver gender & the elderly & good \\
wearing seat belt & varies & marginal \\
\hline
\end{tabular}

\subsubsection{Choice of Denominator}

Any analysis of the factors affecting the likelihood of a fatal collision must involve more than simple vehicle counts. The probability of a fatality or "fatality risk" is defined by dividing by an appropriate denominator. Several denominators that have been used or discussed are shown in Table 1.7. The choice does not mean that other crash/fatality factors are not then considered. It provides the context; it gives the analysis a particular cast.

\footnotetext{
${ }^{6}$ The FARS data have been collected for over 20 years. In that period, new variables (such as seat belt use and airbag deployment) have been added, and the codings of other variables (such as vehicle body type) have been changed. Some variables (such as vehicle travel speed, or whether a crash survivor was wearing a seat belt) are less reliable than others. Some vehicle attributes (such as vehicle weight, make, and model) are decoded from the vehicle identification number (VIN); because NHTSA does not release VINs, it is difficult to verify the accuracy of the VIN decoder used. One vehicle attribute important for our study-light truck weight-is not even provided in the FARS database.
} 


\section{Table 1.7 Some Denominators Adopted to Set the Context of an Analysis}

\begin{tabular}{|l|l|}
\hline registered vehicles & Kahane 1997 \\
crash w/ at least one vehicle towed from scene & U.S. GAO 1995 \\
non-driver front-seat passenger fatality & Evans 1991 \\
not-at-fault driver/struck vehicle in 2-vehicle crash & U.S. GAO 1995, Kahane 1997 \\
pedestrian fatality & Evans 1991 \\
crash reported to the police & Joksch 1998 \\
vehicle miles traveled & information usually not available \\
\hline
\end{tabular}

Let us consider three widely adopted choices to illustrate.

Registered vehicles. In this report, we use ratios of fatalities in two vehicle-crashes in order to minimize exposure/denominator confusion. However, when we can't do that, we adopt per vehicle death rates because the interpretation is relatively clear. But while per vehicle rates are relatively clear, they still introduce significant problems of interpretation. How should one interpret an advertisement by Volvo or Volkswagen showing that fatalities per registered vehicle are relatively low for some models? Are those cars better designed from a safety standpoint? Are they driven less? Or are they being driven by more careful drivers who tend to travel in safer situations? Or all three? ${ }^{7}$ Nevertheless, the number of registered vehicles is frequently used as a denominator, probably because it is available and easy to understand.

Consider young male drivers. Teenage male drivers are estimated to have a fatality risk about 4 times that of 35-50-year-old males, and 7 times that of 35-50-year-old females (Kahane 1997, p. 6). They also tend to drive smaller cars. For this reason, other things being equal, smaller cars are exposed to more high-speed crashes per registered vehicle.

Tow-away crashes. This is another denominator used by analysts. One calculates the number of fatalities per moderately serious crash. It has quite a different meaning than adopting registered vehicles as the denominator since it means that crash likelihood is not part of the analysis. This denominator reduces the severe exposure uncertainties surrounding the causes of crashes but does not eliminate all uncertainties. For example, some vehicles are damaged much more easily than others.

Consider rural diving, excluding expressways. The dependence of risk of serious crashes on rural vs. urban roadways is very strong, and is largely not taken into account by analysts because the information is not readily available. ${ }^{8}$ In a survey of 1999 fatality patterns at the county level, a striking pattern of high traffic deaths per resident population is found in counties with low population density (Maureen Kreple, private communication). For 1980, see Scientific American (1987). There are roughly 6 times as many deaths per person in highly rural counties as in the average of a large sample of urban counties. It may be because high speed crashes are relatively common in rural non-freeway driving. This is potentially important because certain kinds of vehicles, like pickup trucks, are relatively common in

\footnotetext{
${ }^{7}$ We do not dispute that the much higher fatalities per registered vehicle for some powerful sports cars indicate that they tend to be driven by dangerous drivers.

${ }^{8}$ because "urban" is often defined politically in statistical compilations.
} 
rural driving. Unfortunately, information on whether a crash site is really rural or urban is difficult to determine in FARS. ${ }^{9}$

Not-at-fault drivers/vehicles. In its analysis of factors affecting involvement in serious crashes, the U.S. Government Accounting Office (GAO) adopts not-at-fault vehicles in multiple vehicle crashes as a denominator. The assumption is that not-at-fault drivers/vehicles constitute a representative sample of vehicles on the road. For example, the ratio of at-fault male drivers to not-at-fault male drivers in serious two-car crashes determines how much more likely males are to cause such crashes relative to their presence as drivers (U.S. GAO 1995, p. 18). This denominator has the flaw that it is sensitive to traffic density in the areas where the type of vehicle in question tends to be used, e.g., there are relatively few two-vehicle crashes in rural areas and many in Manhattan. Similarly, for part of his analysis, Kahane adopts the denominator temporarily stationary vehicles. (The not-at-fault characteristic of stationary vehicles has the advantage that it does not depend on a police officer's judgement of fault.)

Once a particular denominator has been chosen, analysts usually work to account for the effect of other selected variables. For example, since age and sex of drivers in crashes are known, one can reduce the sensitivity of an analysis to young male drivers by eliminating crashes involving young male drivers or one can also eliminate female drivers. ${ }^{10}$ Or, if one wants to control for several variables, one can fit a form for the dependence of fatalities on those variables, like a linear dependence, and determine the size of the effects using a multiple regression technique. But it should be kept in mind that, with the strong dependence of fatal crashes on the driver and other non-vehicle characteristics, it is difficult to obtain accurate information on the role of the vehicle.

\section{Crash Basics}

In this section we discuss some of the basic physics involved in vehicle crashes. We start with a summary of basic crash terminology. Next, we describe the testing program undertaken by the government to understand crashes and to mitigate their consequences, followed by a discussion of the physics of crashes.

\subsection{Terminology}

The crashworthiness of a type of vehicle describes the risk of serious injury or death for occupants of that vehicle when it has been subject to some level of impact. A high degree of protection, or low risk, corresponds to high crashworthiness. Note that risk is a probabilistic concept.

Crashworthiness depends on three physical aspects of a crash: (1) the occupant coming into serious contact with the hard surfaces of the passenger compartment (such as the windshield,

\footnotetext{
${ }^{9}$ Expanding FARS with information on population density of the county in which a crash occurs might help improve statistical analysis of this exposure variable.

${ }^{10}$ This kind of approach cannot be extensively applied, however, before one runs out of adequate statistics.
} 
steering wheel, or dashboard); (2) intrusion of hard surfaces into the passenger compartment, including distortion of the compartment, with which an occupant may come into serious contact; and (3) acceleration of the passenger compartment and of the occupant (other than striking a hard surface). The acceleration is often irregular in time and complex in directionincluding twisting motions.

Aggressivity refers to the other vehicle in two-vehicle crashes (of some impact level). The aggressivity of a vehicle of Type A is the risk of serious injury or fatality for occupants of vehicles of Type B. Usually aggressivity refers to a comparison of risks, e.g., the aggressivity of a light truck is the risk to a car occupant in a collision with the light truck compared to the risk to the car occupant in a collision with another car.

Compatibility and incompatibility are related to aggressivity. In two-vehicle crashes of a given impact, compatibility is the ability of a vehicle to help protect not only its own occupants, but also the occupants of the vehicle with which it has crashed (Puppini et al. 2000). Incompatibility refers to vehicle design differences that can adversely affect the risk of fatal injury to the occupants of another vehicle. Weight differences are one example. The growth in sales of SUVs has led to a new focus on design characteristics besides weight, such as vehicle height and front end stiffness, that may exacerbate crash incompatibility (Lund et al. 2000, p 77). 


\subsection{Standardized Crash Testing}

The crashworthiness of new vehicle designs is regulated through the Federal Motor Vehicle Safety Standards (FMVSS) and is publicized through a rating program, the New Car Assessment Program (NCAP). Both are managed by NHTSA and are based on standardized crash tests. For frontal collisions, for example, new vehicles are equipped with sophisticated instrumented dummies and crashed head-on into a fixed barrier at 30 miles per hour (mph) for the standard FMVSS208 and $35 \mathrm{mph}$ for NCAP. Indices related to the injury to head, chest (thorax), and other parts are measured. For example, new vehicles must achieve a head impact criterion index of less than 1,000 to meet the FMVSS certification standard. ${ }^{11}$ The NCAP ratings are expressed in terms of a 5-star system.

A striking but not so surprising consequence of the measurements reported under NCAP are the great reductions that have occurred over time in frontal collision ratings for many vehicle models (Hackney, Kahane, and Quarles 1994). The capabilities of engineers to improve products so that they meet challenging requirements in standardized tests is well established in many areas. Although much more difficult to demonstrate, actual crash data also shows improvement correlated with performance in standardized tests (Kahane 1994).

It is noteworthy that some small, light cars perform at the safest levels in the standardized crash tests. While this is a remarkable improvement compared to the safety performance of 1 or 2 decades ago, 5-star performance by light cars should be viewed with some caution: The spectrum of crashes in the real world is much greater than tested; to some extent vehicles may now be designed not for general crashworthiness but to pass the regulatory test. Moreover, the acceleration to which light vehicles are subject in "real world" crashes tends to be greater than those felt in the test against a fixed barrier.

\subsection{Basic Physics}

The universe of fatal crashes is complex. Simple mechanics only describes the most general characteristics and may miss critical factors associated with the complexity of many crashes. But it does suggest ways to organize the analysis, and is valid at the most general semiquantitative level. Where possible, combining the guidance offered by simple physics with actual crash experience is a good way to proceed.

Figure 2.1 shows the cumulative distribution of crashes and fatalities, by $\Delta v$, the vehicle's change in velocity due to the crash (adapted from Evans 1993). Fatality risks, or the probability of fatalities per crash, are shown on the right y-axis. (The data in dots are highly variable where statistics are poor; the gray line is a reasonable approximation.) Focusing on the cumulative fatalities (solid black line), one sees that that a large majority (75\%) of fatalities occur at $\Delta \mathrm{v}$ less than $35 \mathrm{mph}$; these crashes account for more than $99 \%$ of all vehicle crashes. If one could substantially reduce fatalities below $35 \mathrm{mph}$, most of the toll from vehicle crashes would be eliminated. (Note that vehicle speed and the overall change in vehicle velocity, $\Delta \mathrm{v}$, which is the $\mathrm{x}$-axis in Figure 2.1, are not well determined in crash data.

\footnotetext{
${ }^{11}$ Side-impact tests are briefly discussed in the side-impact section below.
} 
The specifics shown on that axis in Figure 2.1 are rough.) Crashes that are fatal in the real world are highly variable. Some crashes are at too high a speed for effective protection, but those crashes are fairly rare.

Figure 2.1 Fatality Risk and Cumulative Crashes and Fatalities (for belted drivers) vs. Change in Velocity of the Car (sketch adapted from Evans 1993)

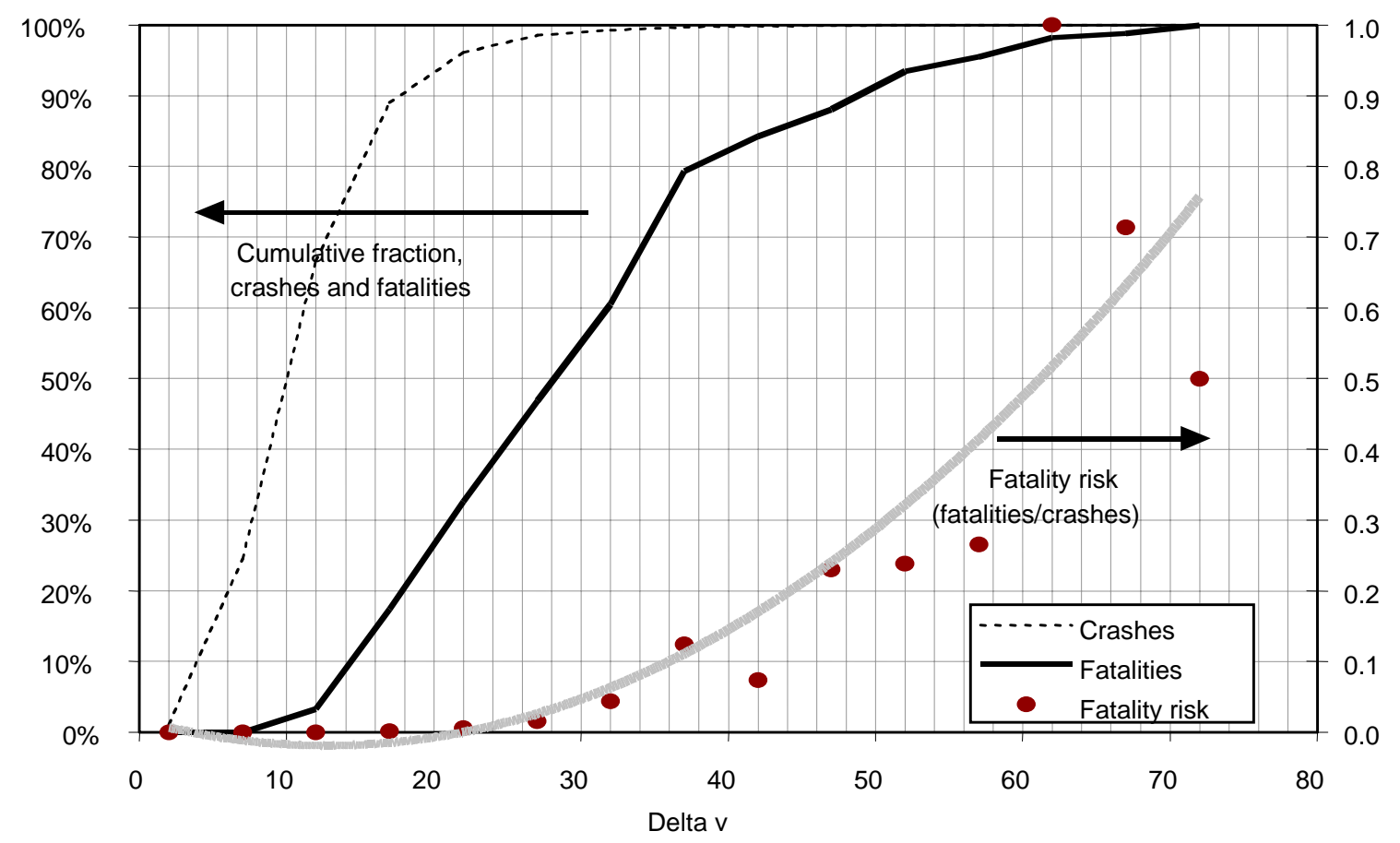

\subsubsection{Momentum in a Vehicle-to-Vehicle Collision}

In many moderately severe crashes, one may be able to neglect occupant's contact with the car's body or with intruding objects. The severity of injury is then determined by the accelerations to which the person is subject, and their duration. The typical collision lasts about one-tenth of a second, or 100 milliseconds.

The collision of two vehicles tends to leave the two vehicles attached. ${ }^{12}$ In the simplest case, when the vehicles initially move directly toward each other, conservation of momentum shows that the lighter vehicle, L, experiences a larger change in velocity than the heavier vehicle, $\mathrm{H}$ :

$$
\begin{aligned}
& \Delta \mathrm{v}_{\mathrm{L}}=\mathrm{m}_{\mathrm{H}}\left(\mathrm{v}_{\mathrm{L}}+\mathrm{v}_{\mathrm{H}}\right) /\left(\mathrm{m}_{\mathrm{L}}+\mathrm{m}_{\mathrm{H}}\right) \\
& \Delta \mathrm{v}_{\mathrm{H}}=\mathrm{m}_{\mathrm{L}}\left(\mathrm{v}_{\mathrm{L}}+\mathrm{v}_{\mathrm{H}}\right) /\left(\mathrm{m}_{\mathrm{L}}+\mathrm{m}_{\mathrm{H}}\right)
\end{aligned}
$$

\footnotetext{
${ }^{12}$ typically for speeds greater than $25 \mathrm{mph}$.
} 
The relationship implied by Equations 2.1 and 2.2 is:

$$
\Delta \mathrm{v}_{\mathrm{L}} / \Delta \mathrm{v}_{\mathrm{H}}=\mathrm{m}_{\mathrm{H}} / \mathrm{m}_{\mathrm{L}}
$$

The masses are inverted relative to the speeds. Thus, a relatively high mass for vehicle $\mathrm{H}$ means that vehicle L experiences the larger change in velocity.

More generally, in collisions with any moveable barrier, vehicles of relatively low mass experience relatively high changes in velocity. So the observed fatality risk is higher for lighter vehicles in those collisions. Therein lies the difficulty for reducing vehicle mass in order to improve fuel economy without compromising crashworthiness.

\subsubsection{Acceleration in a Vehicle-to-Vehicle Collision}

The risk of injury depends on the acceleration experienced. The average acceleration to which the vehicle is subject, $\langle\mathrm{a}\rangle$, is the overall change in the vehicle's velocity, $\Delta \mathrm{v}$, divided by the time, $\mathrm{t}$, over which the crash occurs. ${ }^{13}$

$$
\langle\mathrm{a}\rangle=\Delta \mathrm{v} / \mathrm{t}
$$

Very roughly, $\mathrm{t}=100 \mathrm{~ms}$, but it depends on vehicle design and specifics of the crash. In a head-on collision, vehicle $H$ approaches vehicle $L$ at "closing speed": $v_{c}=v_{L}+v_{H}$. When the vehicles meet and crush against each other, the front of vehicle L moves back, or is crushed, a distance $s$.

$$
\mathrm{S}_{\mathrm{L}}=\text { the crush distance of vehicle } \mathrm{L}
$$

The average speed of the crush is $\mathrm{v}_{\mathrm{c}} / 2$ and the collision time is

$$
\mathrm{t}=\left(\mathrm{s}_{\mathrm{L}}+\mathrm{s}_{\mathrm{H}}\right) /\left(\mathrm{v}_{\mathrm{c}} / 2\right)
$$

Thus the average acceleration has the form

$$
\langle\mathrm{a}\rangle=\mathrm{v}_{\mathrm{c}} \Delta \mathrm{v} /\left[2\left(\mathrm{~s}_{\mathrm{L}}+\mathrm{s}_{\mathrm{H}}\right)\right]
$$

The general form of Equation 2.4, with $<a>$ increasing with speed and decreasing with crush distance, is correct, but the acceleration depends in detail on vehicle structure and crash specifics. And substantial upward deviations in peak acceleration occur.

The important characteristic of Equation 2.4 is the crush distance in the denominator. If well designed, a larger crush distance reduces the forces to which an occupant is subject; it also provides more time and space for internal constraints to act. Relatively small crush space has been a disadvantage of light vehicles because light vehicles have also been small.

\footnotetext{
${ }^{13}$ The time covers the deformations of the vehicles but not their motion as a whole after the deformations.
} 
The equations show the combined effects of mass and size. Equation 2.3 shows that a light vehicle tends to be unsafe in collision with a heavy vehicle; Equation 2.4 shows that a vehicle with a small crush space tends to be unsafe. However, it is difficult to distinguish the effect of weight and crush space/size on safety in crash statistics. We return to that issue in Section 4.

Extremely short acceleration pulses often do not lead to serious injury, but large pulses of several milliseconds do. Consider the crash time broken up into segments $t_{i}$, each of a few milliseconds. In each segment the velocity changes $\Delta \mathrm{v}_{\mathrm{i}}=\mathrm{a}_{\mathrm{i}} \mathrm{t}_{\mathrm{i}}$. During the entire crash:

$$
\Delta \mathrm{v}=\Sigma \mathrm{a}_{\mathrm{i}} \mathrm{t}_{\mathrm{i}}
$$

The peak acceleration, or maximum $a_{i}$, provides a good indication of the severity of injury. The peak is of course higher than the average; how much greater, in various kinds of crashes, is a critical issue for the design of a safe vehicle. Through design of the crush space structures, the crush can be made smoother and the peak brought closer to the average. However, many crashes are complicated. All fatalities cannot be eliminated, and you cannot usually protect enough at high speeds.

A stylized graph of the acceleration to which the passenger compartment is subject in a frontal crash at $35 \mathrm{mph}$ ( 15 meters/second) is shown in Figure 2.2. In this illustration, the maximum acceleration (actually deceleration) is $37 \mathrm{~g}$, where $\mathrm{g}$ is the acceleration due to gravity at the earth's surface. This is a near-fatal crash for a typical belted adult. The figure shows the "softness" of many cars in initial crushing, followed by stiffness when the process reaches hard structures, like the engine. The total area under the curve "a" equals $\Delta \mathrm{v}$ and is roughly fixed by the masses, as shown by Equations 2.1 and 2.2. One way to mitigate the peak acceleration and associated injuries is to lengthen the time of the crash process, e.g., with a larger crush space, as shown by Equation 2.4. Another is to change designs to spread the acceleration more evenly during the time of the crash by adding energy-absorbing structures to even out the deceleration. In this illustration, the peak acceleration is about 2.5 times the average. Many cars and light trucks have stiffer front ends than shown here. 
Figure 2.2 A Schematic Acceleration and Velocity Pattern during the Frontal Crash of a Light Car at 35 mph into a Fixed Barrier

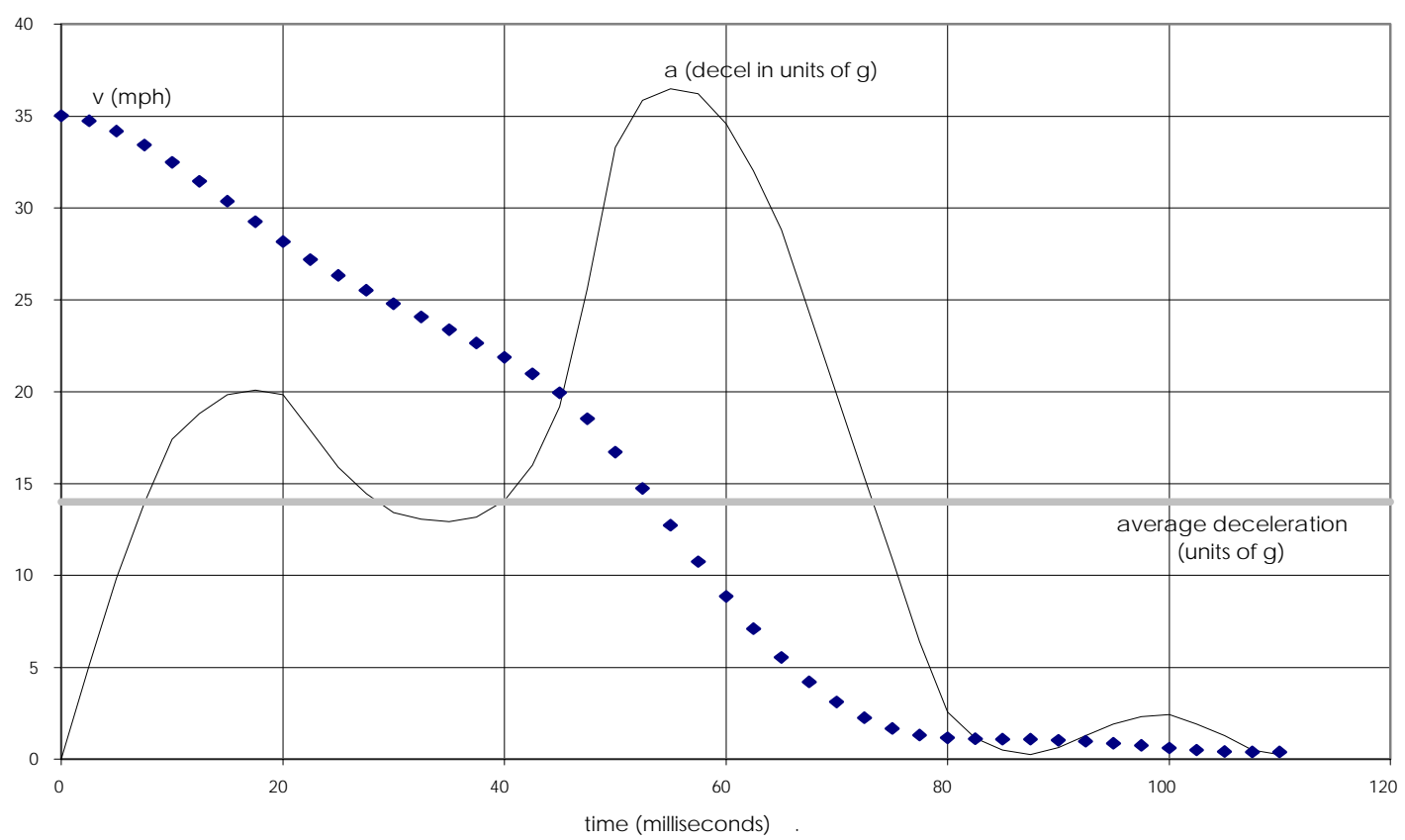

Source: Adapted from Figure 22, http://www.nhtsa.dot.gov/cars/rules/rulings/80g/80gmadym.html

\section{Review of Research on Fatalities in 2-Vehicle Crashes and Vehicle Mass}

In this section we address the risk faced by occupants of vehicles involved in a serious crash. In order to minimize the effect of exposure on fatality risk, we analyze the risk of fatality in two-vehicle collisions and study the ratio of the fatalities of the drivers of the two types of vehicles, i.e., the relative risk. One thus avoids the need to consider the likelihood of a collision.

Many analysts have studied the apparent relationship between vehicle weight and traffic injuries or deaths. To correlate deaths with low vehicle weight seems reasonable - the weights of vehicles in crashes are known and, as just discussed, the laws of physics show that heavier vehicles should experience lower accelerations in a crash.

The laws of physics are also compelling that crush distance should correlate with lower accelerations. However, it is not completely obvious which spatial size is the appropriate measure for a given crash, and the appropriate size is not, in any case, shown in typical vehicle specifications nor is it part of the crash database. As a result, little research has been done on the impact of vehicle size, independent of weight, on traffic fatalities (see, however, Joksch 1998). We will remind the reader that mass-dependence results are actually mass-size dependences. 


\subsection{Car-Car Frontal Collisions ${ }^{14}$}

In order to separate the effects of gross vehicle structure from vehicle mass/size, we consider car-car head-on collisions first. The risk of death usually depends on the acceleration. Empirically it depends strongly on the simple ratio of the masses shown in Equation 2.3. For all collisions between two cars, Joksch finds:

$$
\mathrm{R}_{\mathrm{L}} / \mathrm{R}_{\mathrm{H}} \approx\left(\mathrm{m}_{\mathrm{H}} / \mathrm{m}_{\mathrm{L}}\right)^{\mathrm{n}} \quad \text { with } \mathrm{n}=3
$$

where $\mathrm{R}_{\mathrm{i}}$ is the risk of death in vehicle $\mathrm{i}^{15}$ In other words,

$$
\log \left(\mathrm{R}_{\mathrm{L}} / \mathrm{R}_{\mathrm{H}}\right) \approx 3 \cdot \log \left(\mathrm{m}_{\mathrm{H}} / \mathrm{m}_{\mathrm{L}}\right)
$$

Thus, in a two-car collision it is much more likely for occupants of a light/small car to be killed than for occupants of a heavy/large car. With $n=3$, the equation states, for example, that if car $\mathrm{H}$ is 1.6 as heavy as car $\mathrm{L}$, and also correspondingly larger, then $1.58^{3}=4$ times as many are killed in car $\mathrm{L}$ as in car $\mathrm{H}$ (in a sample of many collisions between them). ${ }^{16}$ (For current model four-door sedans, Cadillac Seville and Honda Civic, the mass ratio is 1.58.) Actually, the power, here quoted as 3, varies with the types of vehicles and other considerations, but occupants of the lighter car are at greater risk in essentially all cases. ${ }^{17}$

In Figure 3.1, the fatality ratio, $\mathrm{R}_{\mathrm{L}} / \mathrm{R}_{\mathrm{H}}$, is shown against the mass ratio, $\mathrm{m}_{\mathrm{H}} / \mathrm{m}_{\mathrm{L}}$, in a $\log$ vs. log plot. The data points for head-on collisions (not shown) form a good straight line with a slope of approximately 3 as just discussed. For cars struck on the driver's side, the outstanding result is the order of magnitude of greater risk for the driver of the struck car than for the driver of the striking car. Side-impact collisions are discussed in the next subsection.

\footnotetext{
${ }^{14}$ Joksch, Massie, and Pichler 1998, Section 5

${ }^{15} \mathrm{n}$ is less if the speeds are very high and both drivers die.

${ }^{16}$ A mass ratio as large as 2 is not common among current model cars in the United States but such high mass ratios are found for light truck-to-car crashes.

${ }^{17}$ The dependence is weak, however, in very high speed collisions because both drivers die.
} 
Figure 3.1 Ratio of Driver Fatalities, $R_{L} / R_{H}$, in Early-1990s Collisions Between Two Cars, by Weight Ratio of the Cars, $m_{H} / m_{L}$, and Collision Configuration

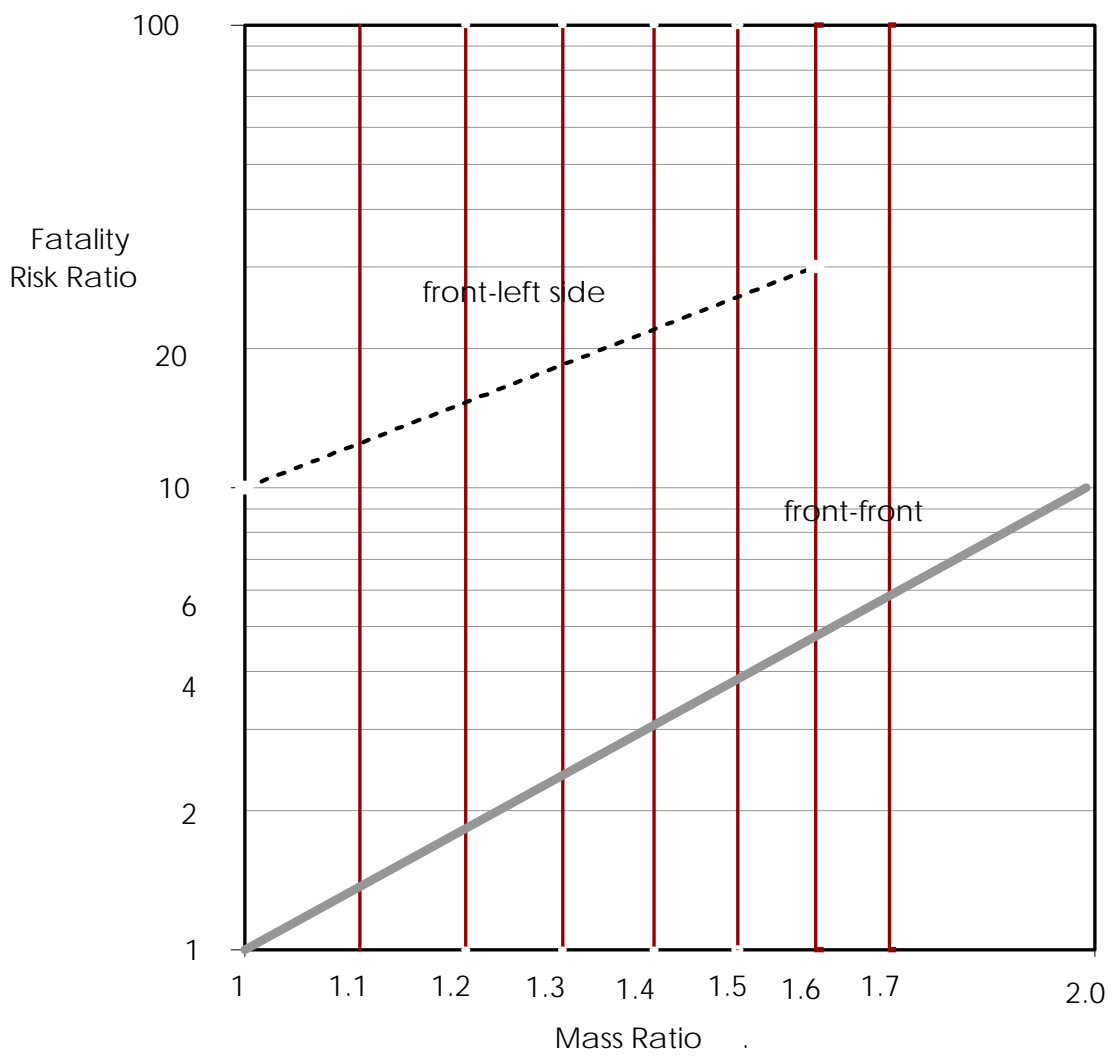

Source: Adapted from Joksch 1998, Figure 4.2-1

\subsubsection{Relative Risk, Recent Model Years}

Changing safety-related technology can be expected to affect these mass-risk relations. We have analyzed the 1999 FARS to obtain the model year dependence of $n$ in Equation 3.2. See Figure 3.2. For the most recent group (model year 1995-99) in Figure 3.2, the fatality risk ratio is significantly smaller than it was in the 1980s. If the average results of Figure 3.2 are assumed to apply to Civics and Cadillacs, the fatality risk ratio is 2.3 . $^{18}$ That is, in such collisions there would be 2.3 deaths of drivers in the Civics for each driver death in the Cadillacs. This is still a large ratio but not nearly as large as for earlier model years. (Note: There were, however, no fatal collisions between 4-door Civics and Sevilles in the past 20 years. Broughton [1994] has pointed out in the English context that rather different classes of cars "meet" less than one might think.)

${ }^{18}$ where, reading numbers off the figure, $\mathrm{e}^{0.112} \cdot 1.58^{1.58}=2.30$. 
Figure 3.2 Model Year Dependence of the Dependence of Fatality Risk Ratio on the Mass Ratio, Head-On Collisions of Car on Car

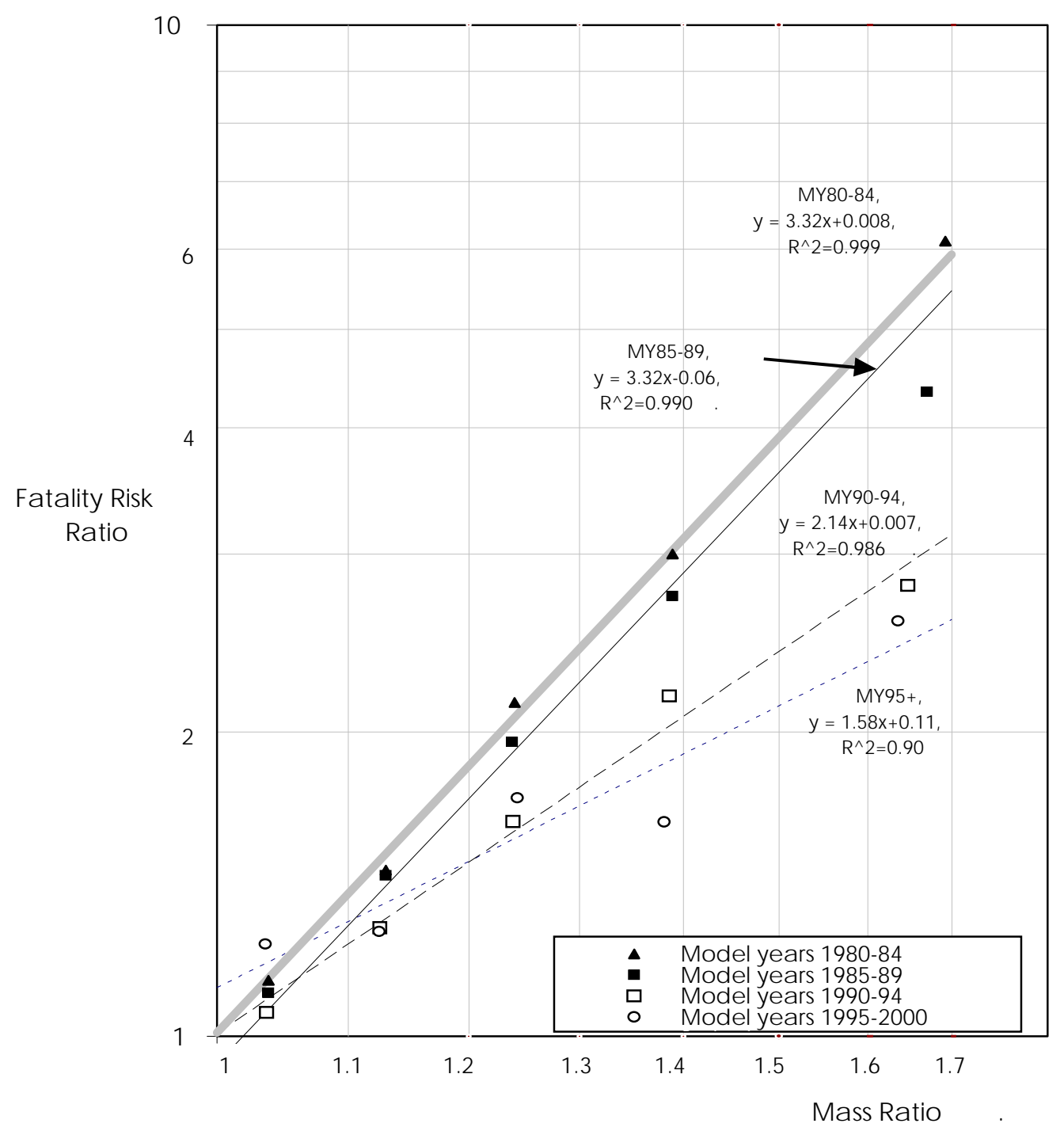

\subsubsection{Absolute Risk}

It is more risky to be in a light/small vehicle than in a heavy/large vehicle if the two collide. Let us ask: What is the risk to society considering the occupants of both vehicles? And how does that risk change as the masses of both vehicles are reduced? Analysts disagree on what crash data tell us about the net effect of mass/size on the deaths in both vehicles. 
In what we find the most convincing analysis, Joksch shows that the dependence of the ratio $\mathrm{R}_{\mathrm{L}} / \mathrm{R}_{\mathrm{H}}$, just discussed, establishes rather generally that in collisions between two cars of the same mass there are fewer fatalities than for collisions between cars of different mass, but the same average mass. That is:

$$
\begin{aligned}
& \mathrm{R}_{\mathrm{L}}+\mathrm{R}_{\mathrm{H}} \text { declines as } \mathrm{m}_{\mathrm{H}} / \mathrm{m}_{\mathrm{L}} \rightarrow 1 \\
& \text { with } \mathrm{m}_{\mathrm{H}}+\mathrm{m}_{\mathrm{L}} \text { unchanged }
\end{aligned}
$$

If the vehicle fleet were altered so that cars had less variation in mass, but were of the same average mass, there would be fewer fatalities. This analysis of Joksch is especially convincing because it is based on fatality ratios and therefore is insensitive to exposure uncertainties.

While this analysis implies that, in order to reduce traffic fatalities, the range of weights in the vehicle fleet should be decreased, it doesn't deal with the average vehicle weight. Should the average be increased or decreased? (Whether vehicle size should be changed independently is usually not discussed.)

These analyses require choosing a denominator, as discussed above. Recent choices made are shown in Table 3.1. All these analyses use some measure of significant crashes, of which fatal crashes are a small fraction. Thus, they ask the question: Given the crash, what are the consequences?

Table 3.1 Two-Car Crashes in Four Analyses, Weight of Both Cars Decreased by 500 lbs.

\begin{tabular}{||l|c|c|c|c|}
\hline \multicolumn{1}{|c|}{ Study } & Denominator & $\begin{array}{c}\text { Model } \\
\text { Years }\end{array}$ & $\begin{array}{c}\Delta \text { Fatality Risk } \\
\text { (both cars) }\end{array}$ & Comment \\
\hline U.S. GAO 1995 & $\begin{array}{c}\text { tow-away } \\
\text { crashes }\end{array}$ & $' 88-' 91$ & $\sim 10 \%$ & $\begin{array}{c}\text { other vehicle } \\
\text { includes light trucks }\end{array}$ \\
\hline Kahane 1997 & $\begin{array}{c}\text { crash into } \\
\text { stationary } \\
\text { vehicle } \\
\text { Jokjury crashes }\end{array}$ & $' 85-' 93$ & $\begin{array}{c}<0 \text { (but not } \\
\text { statistically } \\
\text { significant) }\end{array}$ & $<94$ \\
\hline Joksch 2000 & police reported & $' 91-' 97$ & $<0$ & $\begin{array}{c}<0 \\
\text { airbags excluded } \\
\text { (age corrected) }\end{array}$ \\
\hline
\end{tabular}

Analyzing two-car crash absolute risks, Kahane finds that across-the-board mass reductions lead to an decrease in fatalities in car-to-car collisions, but the result is not statistically significant. Earlier studies (such as Hertz 1997, Evans 1992, U.S. GAO 1995, and earlier NHTSA studies) found that across-the-board mass reductions would increase fatalities. Two important problems confront these analyses: (1) they involve strong assumptions about exposure; and (2) they depend on data from the 1980s, too old (in our view) for analysis of this subtle effect. 


\subsection{Side-Impacts, Car vs. Car}

Most deaths in two-car crashes have been in front-to-front crashes. However, side-impacts have now become more important, probably reflecting improvements in protecting occupants in head-on collisions (see Figures 1.4 and 1.5). The very high risk of drivers in vehicles struck on the side is shown for two crash configurations in Figure 3.1, again as a function of mass ratio. In the case called "front/left side," the front of car A strikes car B on the driver's side. For cars of equal mass, fatalities of car B's driver occur about 6 times more often than fatalities of vehicle A's driver (Joksch, Massie, and Pichler 1988)! ${ }^{19}$ The increase in the fatality ratio with increasing mass ratio discussed above for front-front collisions is seen to be similar for side-impact collisions, although it may be much less strong.

Collisions from the side are rather different from frontal collisions because there is so much less crush space, and the crashes tend to be at lower closing speed. Compared to frontal collisions, intrusion is more important and acceleration less important as the cause of death (Richter et al. 1994). If very light cars recoil more, the intrusion may be less, so that occupants of light vehicles may be at lower risk. Although the ratio of deaths in the struck car compared to those in the striking car is high (see Figure 3.1), the absolute number of sideimpact fatalities in the lightest cars may not be high.

Side-impact collision injuries are becoming a major focus of vehicle design and regulations. A new side-impact standard was introduced in the mid-1990s (FMVSS214), and air bags designed to mitigate moderate-speed impacts from the side are being developed and deployed. These are "torso" bags to protect at the abdomen and "curtain" bags to protect the head. Good results are being obtained for new vehicle models in standardized tests (IIHS 2000). We can be confident that the trend for collisions at angle shown in Figure 1.4 will change for the better, at least moderately.

However, the small crush space is an intrinsic problem; it will be difficult to greatly improve side-impact safety without increasing the crush space. Moreover, the standard crash test is flawed because the bottom of the barrier extends to the ground. In actual side-impact crashes, the effective front of the striking vehicle can be high enough to pass over the sill, creating the danger of intrusion through the door of the struck vehicle.

\subsection{Cars vs. Light Trucks}

Fatalities in car-truck head-on collisions are about 5 times higher in the car than in the SUV, and slightly less for other light trucks (Gabler and Hollowell 1998; Joksch 1998). ${ }^{20}$ In collisions where an SUV strikes the left side of a car, there are 30 driver fatalities in the struck car for each fatality in the striking SUV! In particular, Joksch, Massie, and Pichler (1998) find:

- 5 fatalities in the front-impacted car for each fatality in the SUV

\footnotetext{
${ }^{19}$ This is for equal mass cars, after correcting for the frailty of aged drivers.

${ }^{20}$ Here the light truck is of mass comparable to that of the car. The crashes are in the calendar years 1991-94.
} 
- 30 fatalities in the side-impacted car for each fatality in the striking SUV

- 6 fatalities in the side-impacted car for each fatality in the striking car

Table 3.2a enables comparison of the fatality risk for both drivers in car-car and car-light truck collisions (Joksch 2000, pp. 9-10). The denominator is police-reported crashes. This approach shows, for example, that the ratio of fatalities in SUV-car collisions to those in carcar collisions is $2.32 / 1.28=1.8$. Based on the 1,013 driver fatalities in SUV-car collisions (Table 3.2b), the ratio 1.8 leads to an estimate that about 450 excess drivers' lives were lost in 1999 due to the substitution of SUVs for cars, including station wagons. On this basis, an annual excess of about 2,200 deaths may be associated with the use of light trucks as carsubstitutes. $^{21}$

Table 3.2a Drivers Killed per 1000 Drivers Involved: Car-to-Light Duty Vehicle Collisions by Types of Vehicles

\begin{tabular}{|l|c|c|c|c||}
\hline \multirow{2}{*}{ Death In: } & \multicolumn{4}{|c|}{ Other Vehicle Type } \\
\cline { 2 - 5 } & Car & SUV & Van & Pickup \\
\hline \hline car & 0.64 & 1.98 & 1.57 & 2.11 \\
other vehicle & 0.64 & 0.34 & 0.26 & 0.49 \\
both vehicles & 1.28 & 2.32 & 1.83 & 2.60 \\
\hline
\end{tabular}

Note: The denominator is the expanded number $(1,000)$ of collisions from NASS GES. Data are for 1991-1997.

Table 3.2b Driver Fatalities in Car-to-Car and Car-to-Light Truck Collisions, from FARS 1999

\begin{tabular}{|l|c|c|c|c|}
\hline \multirow{2}{*}{ Death In: } & \multicolumn{4}{|c|}{ Other Vehicle Type } \\
\cline { 2 - 5 } & Car & SUV & Van & Pickup \\
\hline \hline car & 2,850 & 624 & 526 & 1,407 \\
other vehicle & - & 389 & 302 & 956 \\
both vehicles & 2,850 & 1,013 & 828 & 2,363 \\
\hline
\end{tabular}

Physical characteristics responsible for this incompatibility in car-light truck collisions are the high bumper heights, stiff fronts, and high mass of the light truck. In the 15 years from 1984 to 1999, the sales-weighted curb weight of cars increased 284 lbs. while for light trucks it increased 638 lbs. (Heavenrich and Hellman 1999).

Manufacturers and regulators have begun to focus on this incompatibility. Following are two comments from the European car industry. From safety researchers at Renault: "The early seventies were marked by intense activity concerning the topic of "car" compatibility. Twenty years have gone by. Compatibility has made no progress on the roads throughout the world. Some might even claim that it has deteriorated further, with a greater increase in weight for

\footnotetext{
${ }^{21}$ This takes into account the fraction of light trucks used as car substitutes and the scaling up from driver deaths to the total. The comparison of deaths in car-to-pickup crashes with those in car-to-car crashes may be unfair to pickups as a class because more of them are used on dangerous rural roads.
} 
large cars and with the appearance of leisure vehicles of exceptionally aggressive architecture" (Tarriere et al. 1994).

And Prof. Ulrich Seiffert, a distinguished automotive leader, formerly of Volkswagen, is quoted: "To protect the other users, compatibility must be included in the criteria of future legislation. Above all, it is important that the question of compatibility should be considered as a priority over increased speed in collisions against a fixed barrier, or else heavy vehicles would become less compatible" (quoted in Tarriere et al. 1994).

Finally, among U.S. manufacturers, Ford has recently announced several design changes to improve the compatibility between its SUVs and pickups, and other cars, starting in model year 2004 (Bradsher 2001). This is a promising, if modest, beginning. Presumably similar steps are being taken by others.

\section{Review of Research on Safety and Making Vehicles Lighter/Smaller}

\subsection{Analysis of Weight Reduction Based on Fatality Statistics}

In this section we review broad studies that estimate the overall effect of reducing vehicle mass on safety. The most extensive examination of weight reduction is found in the recent studies by Kahane (1997) and Joksch (1998). Kahane examines across-the-board mass reductions using a regression analysis of FARS data for model years 1985-93 and other data. Analyses such as Kahane's do not change weight and sizes independently. Rather, the stated change in weight is really a reduction in weight and size, as well as changes in other features, as they were related in the vehicles at that time. Kahane estimates that a $100 \mathrm{lb}$. reduction in car weights (but not truck weights) would reduce the number of fatalities in "other" cars and for pedestrians, bikers, and motorcyclists, but would increase the number of fatalities in rollovers, collisions with objects, and with light and heavy trucks. The net effect is an annual increase of 302 fatalities (1.13\% increase). The projected increases in fatalities occur because both the weight and size of cars are reduced.

Similarly, Kahane estimates that a $100 \mathrm{lb}$. reduction in light truck weights would reduce fatalities in cars, pedestrians/bikers/motorcyclists, and other light trucks, but would increase the number of fatalities in rollovers, collisions with objects, and collisions with heavy trucks. The net effect is 40 fewer fatalities $(0.26 \%$ decrease). We summarize Kahane's results for reducing the weights/sizes of cars in Table 4.1 and light trucks in Table 4.2. 
Table 4.1 Fatalities Estimated from a $100 \mathrm{lb}$. Weight (and Corresponding Size) Reduction of Cars, Keeping Light Truck Weights Unchanged

\begin{tabular}{|l|ccc||}
\hline Crash Type & $\begin{array}{c}\text { Fatalities, } \\
\text { 1993 Crashes }\end{array}$ & $\begin{array}{c}\text { Effect of 100 lb. } \\
\text { Weight Reduction }\end{array}$ & $\begin{array}{c}\text { Net Fatality } \\
\text { Change }\end{array}$ \\
\hline \hline Principal rollover & 1,754 & $4.58 \%$ & +80 \\
Hit object & 7,456 & $1.12 \%$ & +84 \\
Hit ped./bike/motorcycle & 4,206 & $-0.46 \%$ & -19 \\
Hit big truck & 2,648 & $1.40 \%$ & +37 \\
Hit another car & 5,025 & $-0.62 \% *$ & $-31 *$ \\
Hit light truck & 5,751 & $2.63 \%$ & 302 \\
\hline Total & 26,840 & $1.13 \%$ & 151 \\
\hline
\end{tabular}

* not statistically significant.

Source: Kahane 1997

The principal limitation of Kahane's analysis is that the analysis does not separately deal with size and weight. It also is based on old crash data (1985-93), and, as we have shown, a lot has changed. For example, trends in the mid- and late-1990s show that the tendency for the lightest cars to be unsafe in rollovers declined sharply (see Figure 1.7). We also note that Kahane did not include in his regression models a variable for whether restraints (seat belts and/or airbags) were used. ${ }^{22}$ Restraint use has a major impact on the likelihood of fatality in a serious crash. To the extent restraints vary by vehicle and/or crash type, the relationships Kahane estimates may not reflect inherent differences in vehicle design.

Table 4.2 Fatalities Estimated from a $100 \mathrm{lb}$. Weight (and Corresponding Size) Reduction of Light Trucks, Keeping Car Weights Unchanged

\begin{tabular}{|l|ccc||}
\hline Crash Type & $\begin{array}{c}\text { Fatalities, } \\
\text { 1993 Crashes }\end{array}$ & $\begin{array}{c}\text { Effect of 100 lb. } \\
\text { Weight Reduction }\end{array}$ & $\begin{array}{c}\text { Net Fatality } \\
\text { Change }\end{array}$ \\
\hline \hline Principal rollover & 1,860 & $0.81 \% *$ & $+15^{*}$ \\
Hit object & 3,263 & $1.44 \%$ & +47 \\
Hit ped./bike/motorcycle & 2,217 & $-2.03 \%$ & -45 \\
Hit big truck & 1,111 & $2.63 \%$ & +29 \\
Hit another car & 5,751 & $-1.39 \%$ & -80 \\
Hit light truck & 1,110 & $0.54 \% *$ & $-6^{*}$ \\
\hline Total & 15,312 & $-0.26 \%$ & -40 \\
\hline
\end{tabular}

* not statistically significant.

Source: Kahane 1997

\footnotetext{
${ }^{22}$ This is probably because these variables were not added to the FARS database until 1991. In addition, many researchers doubt the validity of self-reported seat belt usage by vehicle occupants not killed in a serious crash.
} 


\subsection{Mass vs. Size Reduction}

\subsubsection{Background}

"Modern car crashworthiness is based on the concept of using crush distance to decelerate occupants with their compartments. The passenger compartment, or 'safety cage,' is designed as a rigid structure. Front, rear, and side structures outside the cage, called the 'crush' or 'crumple' zones, are designed to absorb crash energy by crushing to reduce the forces reaching the passenger compartment." "Crush distance is the most important safety parameter that doesn't inherently conflict with greater fuel efficiency” (O'Neill 1995, pp. 4 \& 7).

As shown in Section 2, the average deceleration of the passenger compartment in a collision is inversely related to crush space, or distance. The crush space depends on vehicle dimensions, materials, and design. Lightweight materials (high- and ultrahigh-strength steels, aluminum, and plastics) greatly extend the options for increasing crush distances. The importance of crush space relative to mass as deduced from crash fatality statistics is controversial, but it is not difficult to make a convincing argument that increased crush space is a major factor in safety. Increased crush space enables reduction of acceleration in a given crash, provides space for increased stiffness where that is appropriate, and increases the space for deployment of internal constraints and for design of other structures to mitigate crashes.

The high risks associated with short crush spaces are exemplified by the risk of side-impact fatalities as compared to head-on crash fatalities. If a vehicle is very narrow or short, measures for protecting the passenger compartment are likely to require a radical redesign and might be costly (Richter et al. 1994).

\subsubsection{The Joksch Analysis of Wheelbase and Mass}

Car and light truck mass is correlated with size, as represented by wheelbase, so it is difficult to accurately separate the effects of size and mass in fatality statistics. ${ }^{23}$ There is, however, some variation in wheelbase at a given mass: the full width of the wheelbase distribution at a given mass is about $15 \%$, or 15 inches, although cars with relatively long and short wheelbases are becoming rare (Evans 1992; Joksch, Massie, and Pichler 1998). ${ }^{24}$

Joksch, Massie, and Pichler analyze car crashes between 1991 and 1994 with respect to curb weight relative to the normal, or average, weight at a given wheelbase. The "denominator" is police-reported crashes. They obtain results in the form of easy-to-understand graphs for crashworthiness and agressivity in car-to-car collisions, and for crashworthiness of cars in single-car collisions.

Two-vehicle crashes. As is true of other studies, Joksch, Massie, and Pichler find that the risk for occupants decreases with increased weight and size, as they were related in the early

\footnotetext{
${ }^{23}$ Wheelbase is the longitudinal distance between the axles. Wheelbase may not be an especially good measure of size for evaluation of safety but it is the only size measure in FARS.

${ }^{24}$ Evans and Frick (1992) fit a regression line (with a very low correlation coefficient) through the origin to deduce, incorrectly, that fatalities are sensitive to mass but not to wheelbase.
} 
1990s (Joksch, Massie, and Pichler 1998). But they find there is no significant reduction in risk for the drivers of cars heavier than normal for a given wheelbase. For car-to-car collisions, standardized for driver age, they find that:

- Crashworthiness decreases if wheelbase and weight are reduced together at their normal relationship, but "overweight" at a given wheelbase contributes little or nothing to crashworthiness. And, very roughly, a 5\% reduction in wheelbase increases the risk more than a 10\% reduction in weight (Joksch, Massie, and Pichler 1998, Figures 5-6 and 5-8).

- Aggressivity increases with increased wheelbase, as well as with overweight (Figures 5-7 and 5-9). ${ }^{25}$

Thus, car size is important for safety independent of car weight, for two reasons. First, short vehicles tend not to be safe. And making a car heavier than the norm for its size does not make its occupants safer. Second, aggressivity in two-car collisions increases with weight and size, at least for vehicles of early-1990s vintage. It is believed, however, that a heavy vehicle with a soft front can tend to protect occupants of a struck light vehicle, as suggested by Equation 2.4. Achieving such compatibility would be an engineering challenge.

One-vehicle crashes with a stationary object. As others have found for single-car crashes, Joksch, Massie, and Pichler conclude that increased weight and wheelbase, as they were related in the early 1990s, increase occupant safety (Joksch, Massie, and Pichler 1998). But they find increasing weight beyond the norm at a given wheelbase does not increase safety in one-car crashes. And weight decrease at fixed wheelbase appears not to decrease safety, although this is somewhat uncertain (Joksch, Massie, and Pichler 1998, Figures 5-13A and 514B). The argument has frequently been made, to the contrary, that collisions with objects that "give" (like a small tree) are safer for heavy vehicles than for light vehicles. Although true in principle, there is no information that shows this to be an important factor in actual single-vehicle fatalities.

Joksch, Massie, and Pichler are careful to cite the possibility that confounding factors may explain some of these results. For example, "it is conceivable that more aggressive drivers drive overweight cars," making them appear less crashworthy than they are.

\subsection{Light Car Design Studies}

In Europe there is considerable interest in small light cars, very small and light compared to U.S. practice. There is an agreement to produce cars with fuel economy in the range of 3L/100km (79 mpg, neglecting driving cycle differences), and ultra-light "urban cars" are on their way to achieving that goal. In the United States, the Partnership for a New Generation of Vehicles (PNGV) has a similar fuel economy goal, but for vehicles of the same size as a current large U.S. car. In PNGV, the weight reduction would be achieved largely with light materials.

\footnotetext{
${ }^{25}$ This means that the concept that large vehicles offer protection to small ones by carrying crush space with them, as indicated by Equation 2.4, must be viewed critically: crush space in the striking car is not helpful to the struck vehicle unless it is soft enough.
} 
We have not found any European safety analyses dealing with light vehicles built with light materials. A Swiss group has designed and extensively studied the safety of a short light car made of standard materials (Frei et al. 1997). (The length is 3 meters or 118". For comparison, the lengths of some small cars sold in the United States are Honda Civic $=175$ ", Ford Focus 3-door = 168", and Toyota Echo = 163”.) The Swiss group achieved some success, but the car is quite unusual in design and structure. It may support the conclusion of Richter et al. (1994) that making very small size cars safe would be expensive and would add weight.

\section{A Safety-Fuel Economy Scenario}

Fatalities in traffic crashes are declining per vehicle and per driver. Many safety improvements in vehicle and restraint design, highway design, and driver behavior are responsible for this remarkable improvement. But trends in some major kinds of crashes are deeply disturbing. In two-vehicle crashes, three overlapping categories have high fatality rates: light trucks striking cars, side-impacts, and crashes between vehicles of very different weights/sizes. Among one-vehicle crashes, rollovers of SUVs and crashes with stationary objects are slow to decline.

The scenario we envision for the light duty vehicle fleet focuses on changes in the basic physical design and mix of vehicles. The first priority in our scenario is to reduce traffic fatalities, the second to increase fuel economy. Close attention is given to options that would improve both safety and fuel economy, although, where they seem essential, changes that would increase safety but not fuel economy are included.

By "basic physical design" we refer to overall vehicle mass, general aspects of size, and general structure, as distinct from design specifics. While we focus on the basic physical design, it is essential to keep in mind that safety engineering offers many techniques- to improve occupant protection, improve compatibility, improve vehicle stability, and aid crash avoidance - that can be applied to vehicles regardless of their gross physical characteristics.

\subsection{The Scenario}

Fortunately, many potential changes in the vehicle system as a whole support both safety and higher fuel economy. These changes are related to a central theme: narrowing the range of light duty vehicle masses while maintaining or increasing selected spaces. The masses of larger/heavier vehicle types would be reduced, while masses of vehicle types that are now lighter would remain roughly the same. The variety of vehicle styles/types would be maintained through the use of mass-reduction technologies. ${ }^{26}$

\footnotetext{
${ }^{26}$ There is a potential concern about this scenario from a safety standpoint: As the vehicle fleet changes, physical aspects of safety in some segments might be temporarily decreased until older design vehicles are removed from the fleet. However, safety engineering might be used to mitigate transitional problems that might be associated with the scenario.
} 
In addition to mass reduction, the scenario assumes that other aspects of the compatibility of larger/heavier vehicles with smaller/lighter vehicles are improved. Design changes to improve compatibility should not affect fuel economy. For example, SUVs and pickups would have lower bumpers and be soft in the initial frontal crush, so that fatalities in impacted cars would be reduced.

In the scenario, lighter vehicles would stay at roughly their present overall mass, but would incorporate important safety improvements. These would be enabled, from mass and size perspectives, by combining mass-reduction technologies with expansions in dimensions. The lighter vehicles could be significantly wider to enable increased stiffness and padding on the sides. They could have larger frontal crush space. And they could also be higher, raising the sill and seat. Some of such changes would moderately increase the frontal area, or air-drag, component of the "vehicle load" but with the envisioned changes in propulsion efficiency, this class of vehicles would still have much higher fuel economy than at present. ${ }^{27}$

\subsection{Mass-Reduction Technologies}

Two or three major kinds of changes could be made to reduce mass independent of size:

(1) The basic structural design of those light truck car-substitutes that are now body-onframe would instead be unibody, like today's cars, or perhaps space frame. These structures lend themselves to greater compatibility as well.

(2) The use of lightweight materials would be emphasized, such as high- and ultrahighstrength steels, aluminum, and engineering plastics.

(3) High-efficiency propulsion systems would be much lighter than is conventional. The technologies could include: (a) smaller displacement engines with high specific power (high ratio of power-to-displacement); (b) automatic transmissions without torque converter (with motor-shifted standard transmissions using a sophisticated clutch and management to assure smooth acceleration, or with continuously variable transmission); and (c) on-shaft starter-generators, with a $42 \mathrm{~V}$ electrical system, enabling idle-off and other modest hybrid-drive capabilities without incurring a significant battery mass penalty. ${ }^{28}$ The shift busyness and slight shift delays that might characterize driving with a powerful but small engine could interfere with marketing. But minimizing this potential problem should be viewed as an engineering challenge that can be addressed by making use of the minimal hybridelectric capability or appropriate transmission technology.

Although these technologies exploit the major energy losses in present vehicles, no particular technology is essential to our scenario. The technologies listed show that efficiency

\footnotetext{
${ }^{27}$ It is assumed that ultra-light vehicles would not be a significant part of the mix on major roads. Small "urban" cars, of interest in Europe and Japan, might possibly have a role in the United States, but we assume in this scenario that those very small cars do not come into widespread use on high-speed roads. Our focus is the safety of vehicles in the general high-speed environment of the United States, so we don't consider these small urban cars.

${ }^{28}$ The motor-driven transmission, as envisioned, is not produced today, and the integrated starter generator may only be in a VW Golf. However, the pace of change in such electrical components and controls is indeed rapid.
} 
improvement can accompany weight reduction. It is assumed that new vehicles embodying major mass or size changes will be built from the ground up, so this is a long-term scenario for wide-scale adoption. Major improvements are more difficult to achieve by dropping technologies into existing designs.

To illustrate with particular numbers, we assume that the mass range (curb weights) of most light duty vehicles would be brought essentially to 2,400-3,300 lbs. The present distribution of inertial weights (curb weight plus $300 \mathrm{lbs}$.) is shown in Figure 5.1. Mass reductions of up to $33 \%$ are projected, e.g., a 4,800 lb. curb weight light truck car-substitute is redesigned to achieve 3,200 lb. curb weight. To achieve such major mass reductions while maintaining the size and performance characteristics that attract customers would be a major engineering challenge. And there would be challenges in redesigning effective crush regions using new materials.

Figure 5.1 Sales (Thousand) by Inertial-Weight Group (lbs.) for Model Year 2000

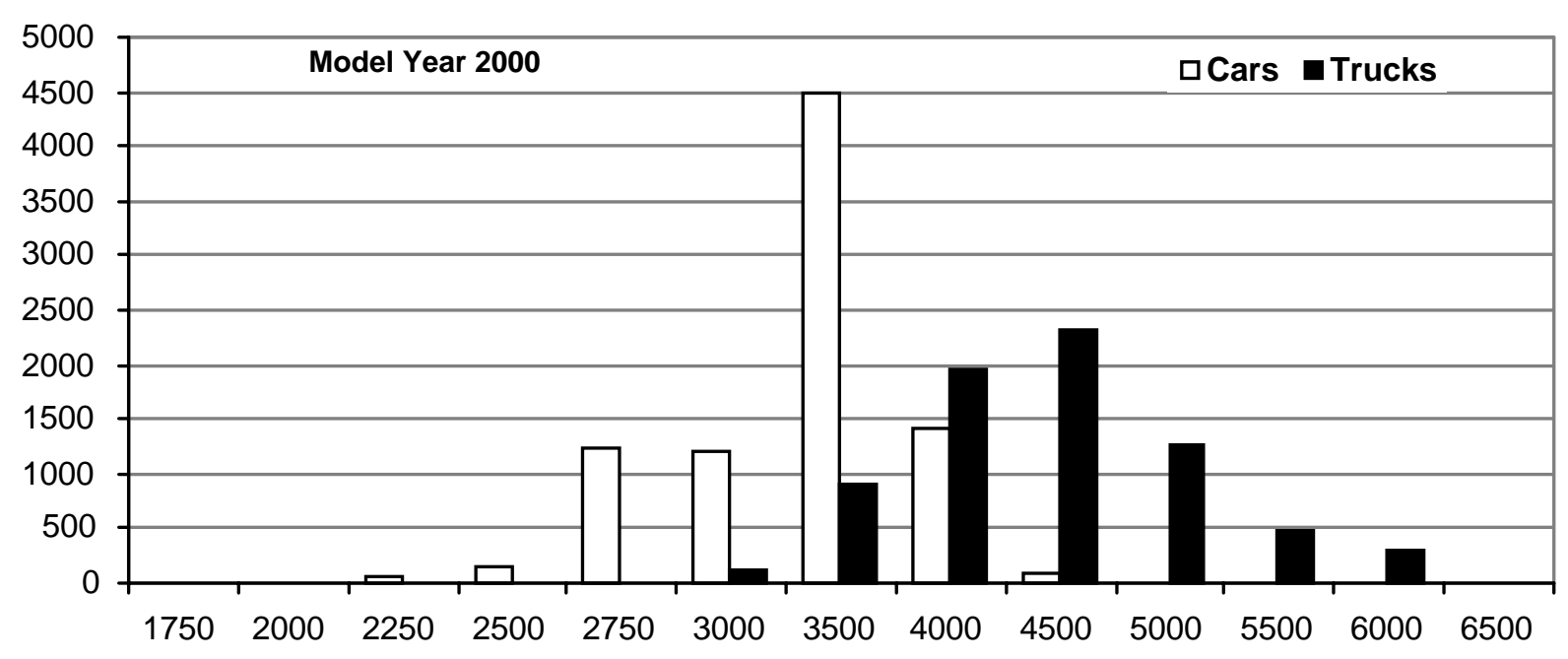

Note: Inertial test weight is curb weight plus $300 \mathrm{lbs}$. Weight scale is not linear. Weight classes are defined in 40CFR86.129-80.

Source: Heavenrich and Hellman 2000, Appendix G

\subsection{Lives Saved}

We only make rough estimates of the impact of our scenario on future traffic fatalities, and only for the two most critical types of crashes: crashes between two light duty vehicles, and crashes of light duty vehicles with stationary objects. We estimate that bringing vehicle masses together (by making what are now heavier vehicles lighter while making lighter vehicles larger at the same weight) and increasing other compatibility characteristics would save about 2,200 lives a year in two-vehicle crashes, based on 1999 fatality rates. This estimate is based solely on the excess of deaths in light truck-to-car crashes (as analyzed in Section 3.3) for those light trucks used as car substitutes. In this scenario there would also be many lives saved in car-to-car crashes, but some extra lives lost in heavy truck-to-light duty vehicle crashes. 
For fatalities in one-vehicle crashes with stationary objects, we estimate that weight reduction without size reduction would lead to an increase of, at most, half of that estimated by Kahane because our scenario calls for selected changes in the historical correlation between vehicle weight and size. This corresponds to a $0.65 \%$ increase in this crash category per $100 \mathrm{lb}$. weight reduction $(0.65 \%$ is roughly half of the average effect on car and truck weight reduction in Tables 4.1 and 4.2). We propose the decrease in weight for a small part of the existing car fleet and most of the light truck fleet (the classes 3,700 lb. curb weight and above). This implies an average 1,000 lb. decrease in the mass of these light trucks and heavy cars. We thus estimate an increase of about 360 deaths per year in one-vehicle crashes. ${ }^{29} \mathrm{We}$ believe this to be an overestimate, given the continuing practical opportunities to improve safety technologies.

Neglecting such further opportunities, we thus estimate that about two thousand lives would be saved annually.

\subsection{Fuel Economy Improvement}

The reductions in vehicle masses and the adoption of lightweight high-efficiency propulsion technologies lie between the "moderate" and "advanced" packages of fuel economy technologies described in DeCicco, An, and Ross (2001). In that analysis, the average improvements in the fuel economy are $47 \%$ and $70 \%$ for the moderate and advanced cases, respectively. (These fuel economies are all regulatory test values, where the car and light truck standards are 27.5 and $20.7 \mathrm{mpg}$, respectively. The combined fuel economy for cars and light trucks with 1999 sales weighting is $24.1 \mathrm{mpg}$.) The projected combined fuel economy improvement is $55 \%$, just over one half. The percent improvement on the road would be somewhat better because the vehicle accessories, especially air conditioning, can be much more efficient when driven electrically as would be the case with the integrated startergenerator.

\subsection{Qualitative Cost Impacts}

There would be increases in manufacturing cost-per-unit in this scenario if the lightweight materials aluminum and engineering plastics, which are more expensive than conventional materials, are substantially involved. However, some mass reductions can be realized without those materials. Ultralight steel techniques can trim 15-20\% off of today's steel bodies, as well as associated parts. Thus, substantial substitution of more-costly materials may only be needed for the most challenging vehicles-the heavier light truck car substitutes in noncommercial use. We have not made a detailed analysis, but see DeCicco, An, and Ross (2001).

There would, on the other hand, be major development and re-tooling costs distinct from the per-unit manufacturing costs. But design aspects of the vehicle market are now evolving

\footnotetext{
${ }^{29}$ This is the product of an average $1000 \mathrm{lb}$. weight reduction for the group of heavy light duty vehicles, the $0.65 \%$ increase per $100 \mathrm{lb}$. reduction, 11,000 deaths in this category (from Table 1.2), and the fraction 0.50 for the group of vehicles with reduced masses $(10 * 0.65 \% * 11,000 * 0.5=360)$.
} 
rapidly. The development and tooling costs may be no higher than those under a business-asusual scenario in which automakers make little use of the safety opportunities associated with the basic physical design approach sketched here. It may be more a matter of which choices are made within a given product development budget than an issue of this approach requiring higher budgets.

The exception would be special costs associated with increased use of higher cost materials. However, these possible impacts can be viewed in the context of delaying some "marketable" vehicle features, even some things sold on the basis of safety (such as telematics systems, warning devices, etc.), with marginal actual safety advantages when compared to the potentially large advantages from designing physically compatible vehicles. Thus, delaying safety technologies that might have low real world safety value could be a way to save development dollars for the more fundamental design enhancements we propose. 


\section{References and Literature Reviewed}

Bendjellal, F., G. Walfisch, C. Steyer, P. Ventre, J.Y. Foret-Bruno, X. Trosseille, and J.P. Lassau. 1997. The Programmed Restraint System-A Lesson from Accidentology. SAE \#973333.

Bradsher, K. 2001. New York Times, January 9.

Broughton J. 1994. The Theoretical Basis for Comparing the Accident Record of Car Models. Project Report 70. Crowthorne Berks, U.K.: Transport Research Laboratory.

DeCicco, John, Feng An, and Marc Ross. 2001. Technical Options for Improving the Fuel Economy of U.S. Cars and Light Trucks by 2010-2015. Washington, D.C.: American Council for an Energy-Efficient Economy.

Evans, Leonard. 1991. Traffic Safety and the Driver. Van Nostrand Reinhold. 1993. "Driver Injury and Fatality Risk in Two-Car Crashes versus Mass Ratio Using Newtonian Mechanics." In the 37th Annual Proceedings, Association for the Advancement of Automotive Medicine, 313-327.

Evans, Leonard, and M.C. Frick. 1992. "Car Size or Car Mass: Which Has Greater Influence on Fatality Risk?" American Journal of Public Health, August, 82 (8), 1105-1112.

Frei, P., R. Kaeser, R. Hafner, M. Schmid, A. Draggan, L. Wingeler, M.H. Muser, P.F. Niederer, and F.H. Walz. 1997. Crashworthiness and Compatibility of Low Mass Vehicles in Collisions. SAE 970122.

Friedman, Donald, Keith D. Friedman, Clarence M. Ditlow, and Douglas C. Nelson. 1991. The Safe Road to Fuel Economy. Goleta, Calif: MCR Technology and Washington, D.C.: Center for Automotive Safety.

Gabler, H.C., and W.T. Hollowell. 1998. The Aggressivity of Light Trucks and Vans in Traffic Crashes. SAE 980908.

Gillespie, Thomas D. Fundamentals of Vehicle Dynamics. SAE 1992, Chapter 9.

Griffin, Lindsay III. 1989. A Criticism of Evans' Double Pair Comparison Method. Texas Transportation Institute.

Hertz, Ellen. 1997. The Effect of Decreases in Vehicle Weight on Injury Crash Rates. NHTSA, DOT/HS 808575.

Hackney, J.R., C.J. Kahane, and V.R. Quarles. 1994. The New Car Assessment ProgramHistorical Review and Effect. \#941052. Society of Automotive Engineers. 
Heavenrich, Robert, and Karl Hellman. 1999. Light-Duty Automotive Technology and Fuel Economy Trends through 1999. U.S. Environmental Protection Agency, Office of Mobile Sources.

[IIHS] Insurance Institute for Highway Safety. 2000. News Release of December 14. http://www.highwaysafety.org.

Jawad, Saad J.W. 1998. Compatibility Study in Frontal Collisions-Mass and Stiffness Ratio. NHTSA 98-S1-O-14.

Jewkes, D.B., Per Lovsund, and D.C Viano. 1999. Safety of a Downsized Vehicle Fleet: Effects of Mass Distribution, Impact Speed and Inherent Protection in Car-to-Car Crashes. SAE SP-1442, 75-84, 1999-01-0074.

Joksch, Hans. 1998. Fatality Risks in Collisions Between Cars and Light Trucks. NHTSA, DOT/HS 808802.

2000. Vehicle Design versus Aggressivity. http://wwwnrd.nhtsa.dot.gov/pdf/Crashworthiness/DOT_HS_809194.pdf. NHTSA, DOT/HS 809 194.

Joksch, Hans, Dawn Massie, and Robert Pichler. 1998. Vehicle Aggressivity: Fleet Characterization Using Traffic Collision Data. http://wwwnrd.nhtsa.dot.gov/pdf/Crashworthiness/aggress1.pdf. NHTSA, DOT/HS 808679.

Kahane, Charles J. 1994. Correlation of NCAP Performance with Fatality Risk in Actual Head-On Collisions. http://www.nhtsa.dot.gov/cars/rules/regrev/evaluate/ 808061.html. NHTSA, HS 808061.

- 1997. Relationships Between Vehicle Size and Fatality Risk in Model Year 1985-93 Passenger Cars and Light Trucks. http://www.nhtsa.dot.gov/cars/rules/regrev/ evaluate/808570.html (summary only). NHTSA, DOT/HS 808570.

- 1998. Fatality Reduction by Air Bags: Analyses of Accident Data Through Early 1996. NHTSA, DOT/HS 808470.

- 2000. Fatality Reduction by Safety Belts for Front-Seat Occupants of Cars and Light Trucks. NHTSA, DOT/HS 809199.

Kahane, Charles J. and Terry Klein. 1991. Effect of Car Size on Fatality and Injury Risk, NHTSA.

Khazzoom, J.D. 1991. "Supplemental Material for the Testimony of J.D. Khazzoom before the Consumer Subcommittee, Committee on Commerce, Science, and Transportation, US Senate." April 10. 
— 1994. "Fuel Efficiency and Automobile Safety: Single Vehicle Highway Fatalities for Passenger Cars." The Energy Journal 15 (4), 49-101.

Klein, Terry M. 1992. A Statistical Analysis of Vehicle Rollover Propensity and Vehicle Stability. SAE \# 920584.

Kockelman, Kara. 2000. "To LDT or Not to LTD, An Assessment of the Principal Impacts of Light-Duty Trucks." Paper presented at the Transportation Research Board's $79^{\text {th }}$ Annual Meeting, January.

Lund, Adrian, B. O’Neill, J.M. Nolan, and J. Chapline. 2000. Crash Compatibility Issue in Perspective. SAE SP-1525, 77-82, 2000-01-1378.

Lund, Adrian, and Janella Chapline. 1999. Potential Strategies for Improving Crash Compatibility in the US Vehicle Fleet. SAE SP-1442, 33-42, 1999-01-0066.

Malliaris, C., and K.H. Digges. 1999. Crash Exposure and Crashworthiness of Sport Utility Vehicles. SAE 1999-01-0063.

Massie, Dawn, K.L. Campbell, and A.F. Williams. 1995. Traffic Accident Involvement Rates by Driver Age and Gender. Accident Analysis and Prevention, 27 (1), 73-87.

Massie, Dawn, P.E. Green, and K.L. Campbell. 1997. Crash Involvement Rates by Driver Gender and the Role of Average Annual Mileage. Accident Analysis and Prevention, 29 (5), 675-685.

Mizuno, Koji, T. Umeda, and H. Yonezawa. 1997. The Relationship Between Car Size and Occupant Injury in Traffic Accidents in Japan. SAE \#970123.

Nash, Carl. 1993. "Discussion of Evans' Paper: Driver Injury \& Fatality Risk." In the 37th Annual Proceedings, Association for the Advancement of Automotive Medicine, 333340.

National Research Council. 1992. Automotive Fuel Economy: How Far Should We Go? National Academy Press.

Nolan, Joseph M, M.R. Powell, C.A. Preuss, and A.K. Lund. 1999. “Actors Contributing to Front-Side Compatibility: A Comparison of Crash Test Results." In the $43^{\text {rd }}$ Stapp Car Crash Conference, 13-24.99SC02.

[NOPUS] National Occupant Protection Use Survey. 2000. http://www.nhtsa.dot.gov/people/ ncsa/pdf/00-035.pdf. NHTSA.

O'Neill, B. 1995. The Physics of Car Crashes and the Role of Vehicle Size and Weight in Occupant Protection. Insurance Institute for Highway Safety. 
Plotkin, S. 1995. Advanced Automotive Technology: Visions of a Super-Efficient Family Car. OTA-ETI-638. U.S. Congress Office of Technology Assessment.

Puppini, R., M. Martinotti, M. Di Leo, and P.L. Ardoino. 2000. Vehicle Aggressivity and Compatibility in Automotive Crashes. SAE-2000-01-1373.

Richter, B., N. Jahn, R. Sinnhuber, C. Stender, R. Zobel, and G. Zogalla. 1994. How Safe Can Lightweight Cars Be? An Analytical Study of the Limits of Passive Safety. In the $14^{\text {th }}$ International Technical Conference on Enhanced Safety of Vehicles, 622, paper 94-S4-O-17. Munich.

Robertson, L.S. 1993. "Size, not Mass of Car Affects Severity of Injury in Accidents.” Letter. American Journal of Public Health, August, 83, 768. See also M. Susser, "Talking Past Each Other..." Editorial. 83, 642-643.

Scientific American, 1987. August, 257 (2) 28.

Tarriere, Claude, Y. Morvan, C. Steyer, and D. Bellot. 1994. "Accident Research and Experimental Data Useful for an Understanding of the Influence of Car Structural Incompatibility on the Risk of Accident Injury." In the $14^{\text {th }}$ International Technical Conference on Enhanced Safety of Vehicles, 593, paper 94-S4-O-14. Munich.

[U.S. TEDB] U.S. Department of Energy. 2000. Transportation Energy Data Book, Edition 20. Prepared by Stacy C. Davis, Oak Ridge National Laboratory. Chapter 7.

U.S. Bureau of the Census. 1997. Vehicle Inventory and Use Survey.

[U.S. GAO] U.S. Government Accounting Office. 1994. Highway Safety: Factors Affecting Involvement in Vehicle Crashes.

. 1995. Highway Safety: Causes of Injury in Automobile Crashes.

Ward's. 2001. Motor Vehicle Facts and Figures 2000. Southfield, Mich.

Wood, Denis P. 1997. "Safety and the Car Size Effect: A Fundamental Explanation," Accident Analyis and Prevention, 29 (2), 139-151.

Zobel, Robert. Accident Analysis and Measures to Establish Compatibility. SAE SP-1442, 2132, 1999-01-0065. 